\title{
Benefits of Zebrafish Xenograft Models in Cancer Research
}

\author{
Xingyu Chen ${ }^{1,2 \dagger}$, Yongyun $\mathrm{Li}^{1,2 \dagger}$, Tengteng Yao ${ }^{1,2}$ and Renbing Jia ${ }^{1,2 *}$ \\ 'Department of Ophthalmology, Ninth People's Hospital, Shanghai Jiao Tong University School of Medicine, Shanghai, \\ China, ${ }^{2}$ Shanghai Key Laboratory of Orbital Diseases and Ocular Oncology, Shanghai, China
}

OPEN ACCESS

Edited by:

Alexei Degterev,

Tufts University, United States

Reviewed by:

Rita Fior,

Champalimaud Foundation, Portugal Jessica Blackburn

University of Kentucky, United States

*Correspondence:

Renbing Jia

renbingjia@sjtu.edu.cn orcid.org/0000-0001-6642-7451

†These authors have contributed equally to this work

Specialty section:

This article was submitted to

Cell Death and Survival,

a section of the journal

Frontiers in Cell and Developmental

Biology

Received: 12 October 2020

Accepted: 11 January 2021

Published: 11 February 2021

Citation:

Chen X, Li Y, Yao T and Jia R (2021) Benefits of Zebrafish Xenograft Models in Cancer Research. Front. Cell Dev. Biol. 9:616551. doi: 10.3389/fcell.2021.616551
As a promising in vivo tool for cancer research, zebrafish have been widely applied in various tumor studies. The zebrafish xenograft model is a low-cost, high-throughput tool for cancer research that can be established quickly and requires only a small sample size, which makes it favorite among researchers. Zebrafish patient-derived xenograft (zPDX) models provide promising evidence for short-term clinical treatment. In this review, we discuss the characteristics and advantages of zebrafish, such as their transparent and translucent features, the use of vascular fluorescence imaging, the establishment of metastatic and intracranial orthotopic models, individual pharmacokinetics measurements, and tumor microenvironment. Furthermore, we introduce how these characteristics and advantages are applied other in tumor studies. Finally, we discuss the future direction of the use of zebrafish in tumor studies and provide new ideas for the application of it.

\section{Keywords: zebrafish model, tumor visualization, pharmacokinetics, tumor microenvironment, tumor model}

\section{INTRODUCTION}

The implantation of tumors into zebrafish has become an emerging model platform in cancer studies. The implanted cancer cells include patient-derived primary cells and laboratory cell lines. Traditional patient-derived xenografts (PDXs) are established from tumor cells or masses isolated from patients during biopsy or excision and are implanted into a model animal, such as immunodeficient mice. To some extent, PDXs retain the heterogeneity of the patient's primary tumor and possess a stable biological profile as it relates to gene expression and mutation (Hidalgo et al., 2014). Mounting evidence has indicated that PDX models maintain the biology of the tumor and can predict the efficacy of drugs based on direct comparisons of drug efficacies in patients and in mice inoculated with corresponding xenografts (Tentler et al., 2012; Siolas and Hannon, 2013; Hidalgo et al., 2014; Rosfjord et al., 2014). Over the past 40 years, mouse patientderived xenografts (mPDXs) have played an unparalleled role in preclinical trials and personalized medicine. However, the primary issue for their widespread clinical application is the large number of tumor samples required and the time needed for the xenograft to grow. Currently, zebrafish patient-derived xenograft (zPDX) models have elicited increasing attention from researchers in cancer fields because these models can also provide valuable information on the molecular biology of tumors and personalized therapeutic choices for patients with diverse cancer types (Bentley et al., 2015; Lin et al., 2016; Fior et al., 2017; Gaudenzi et al., 2017).

Cancer cells implanted into zebrafish are derived from various types of malignancies, such as germ cell tumors, leukemia, lymphoma, melanoma, sarcoma, neuroblastoma, and various epithelial cancers originating from the neuroendocrine system (i.e., liver, gastrointestinal tract, 
colon, pancreas, prostate, lung, ovary, and breast) (Haldi et al., 2006; Marques et al., 2009; Weiss et al., 2009; Zhao et al., 2009; Corkery et al., 2011; Latifi et al., 2011; Ghotra et al., 2012; He et al., 2012; Smith et al., 2013; Chapman et al., 2014; Vaughan et al., 2015; Gaudenzi et al., 2017; Lin et al., 2019; Wong et al., 2019).

Regarding its application, the zebrafish model is a highthroughput and low-cost animal model for predicting the efficacy of personalized cancer therapy and exploring mechanisms that drive tumor growth, metastasis, and responses to therapy (Keller and Murtha, 2004; Patton et al., 2005; Zon and Peterson, 2005; Barros et al., 2008; Park et al., 2008; Marques et al., 2009; Smith et al., 2010; Eguiara et al., 2011; Nguyen et al., 2012; Chen et al., 2014; Tang et al., 2014; Mandelbaum et al., 2018; Wong et al., 2019). Zebrafish are tiny and can hatch 150-200 eggs every week, which meets the high-throughput and low-cost requirements for a viable animal model. The zebrafish model can not only be applied to study tumor angiogenesis, cell invasiveness and drug responses in a time- and cost-effective manner but also serve as a real-time in vivo platform for personalized cancer treatment (Wu et al., 2017; Rebelo de Almeida et al., 2020). In addition, the zebrafish genome project revealed sequence conservation of multiple genes and identified zebrafish orthologs for $82 \%$ of genes related to human disease, suggesting a high interspecies conservation of molecular pathways between zebrafish and humans (Chen and Fishman, 1996; Granato and NussleinVolhard, 1996; Howe et al., 2013; Tulotta et al., 2016).

However, there are also limitations and challenges of using zebrafish as a model in cancer research, including inconsistencies with generating models, high mortality after injection, disparity in protocols among laboratories, different body temperatures between fish and humans, and poor reproducibility. Despite these shortcomings, zebrafish are still being applied as a promising model in tumor research.

In this review, we focus on applications of the zebrafish model of implanted tumors to facilitate cancer studies and predict the efficacy of personalized cancer treatment. Characteristics of the zebrafish model, such as the establishment of various tumor models, antitumor drug pharmacokinetics, and the tumor microenvironment (TME) (all of which are of special interest in cancer research), are discussed in detail (Figure 1).

\section{CLASSIC CHARACTERISTICS OF THE ZEBRAFISH XENOGRAFT MODEL}

A tumor model can be created in both embryonic and adult zebrafish. There is currently an immune-deficient adult zebrafish strain that lacks T, B, and natural killer (NK) cells and can be used to establish xenograft models for studying new therapies (Traver et al., 2003; Langenau et al., 2004; Patton et al., 2005; Stoletov et al., 2007; Blackburn et al., 2012; Tchoghandjian et al., 2012; Tang et al., 2014; Moore et al., 2016; Drabsch et al., 2017; Yan et al., 2019). For instance, optically clear prkdc ${ }^{-} /^{-}, i l 2 r g a^{-} /^{-}$ transgenic zebrafish, which lack an adaptive immune system and NK cells, can be engrafted with human cancer cells at $37^{\circ} \mathrm{C}$ (Yan et al., 2019; Costa et al., 2020a). If the xenograft is transplanted at early embryonic stages [blastula stage to $48 \mathrm{~h}$ postfertilization (hpf)], at which point the adaptive immune system has not yet matured, the procedure does not require immune suppression (Lam et al., 2004; Haldi et al., 2006; Nicoli et al., 2007; Konantz et al., 2012; White et al., 2013). It has been reported that cancer cells labeled with a fluorescent marker (such as CM-DiI) and injected into 48-hpf embryos can be tracked for more than 7 days post fertilization (7 dpf) (White et al., 2013; Wu et al., 2017). During this period, the size and shape of the implanted tumor can be evaluated by fluorescence microscopy, confocal microscopy, pathological biopsy, and other techniques (Pontes et al., 2017).

Other transgenic zebrafish strains, such as the "Casper" line $\left(\right.$ roy $^{-/-} ;$nacre $\left.{ }^{-/-}\right)$and vascular-specific green fluorescent protein (GFP) strains, might be considered useful tools for other cancer-related studies (Zon and Peterson, 2005; Haldi et al., 2006; Mizgireuv and Revskoy, 2006; Marques et al., 2009; Stoletov et al., 2010; Eguiara et al., 2011; Zhao et al., 2011a,b; D’Agati et al., 2017; Pontes et al., 2017; Lin et al., 2019). The pigmentdeficient "Casper" strain provides optically clear visualization to observe xenograft cancer cells (White et al., 2008; Cho et al., 2015; Heilmann et al., 2015; Li et al., 2015; Tang et al., 2016; D’Agati et al., 2017). The transparency of the zebrafish body makes it possible to track two or more types of cells labeled with different fluorescent colors and explore their interaction (Corkery et al., 2011; Liu and Leach, 2011; Wang et al., 2015; Vazquez Rodriguez et al., 2017; Sun et al., 2019). The "Casper" strain is also useful for tracking extracellular vesicles (EVs) released from tumors and dissecting their role in forming the metastatic niche in vivo (Hyenne et al., 2019).

Tumor neovascularization is essential to the initiation, progression, and invasion of cancers (Folkman, 1971, 1989; Chung et al., 2010; Jászai and Schmidt, 2019). Exploration of the mechanism of neovascularization in tumors and the development of antiangiogenic agents to inhibit tumor neovascularization are two focuses of tumor therapy studies (Folkman, 1989; Bergers et al., 1999). The $\operatorname{Tg}($ fli:eGFP) zebrafish line with GFP-labeled vasculature contributes largely to studies on the mechanism of tumor neovascularization and evaluations of the efficacy of antiangiogenic agents (Tran et al., 2007; Fior et al., 2017; Gaudenzi et al., 2017; Britto et al., 2018, 2019; Cirello et al., 2018; Garcia-Caballero et al., 2018). For instance, researchers directly observed and compared the in vivo conditions needed to create GFP-positive vessels in the zebrafish strain $\operatorname{Tg}(k d r l: e G F P) s 843$, a transgenic zebrafish line expressing eGFP under the control of the endothelial $k d r l$ promoter. These models are grafted with normal DU-145 prostate cancer cells and transfected with four microRNAs (miR-125a, miR-320, miR-487b, and miR-492) (Chiavacci et al., 2015). Studies have concluded that angiogenic growth factors are locally released by angiogenic tumor cells, and the microRNAs applied can inhibit this process (Chiavacci et al., 2015). The $\operatorname{Tg}(f l i: \mathrm{eGFP})$ zebrafish line is also used to test the effect of drugs on blocking or preventing tumor neovascularization (Franich et al., 2020).

Although zebrafish are not mammals, they have several tissues, organs and glands whose functions are similar to those of mammals; these include the musculoskeletal and cardiovascular systems, eyes, brain, liver, heart, gastrointestinal 


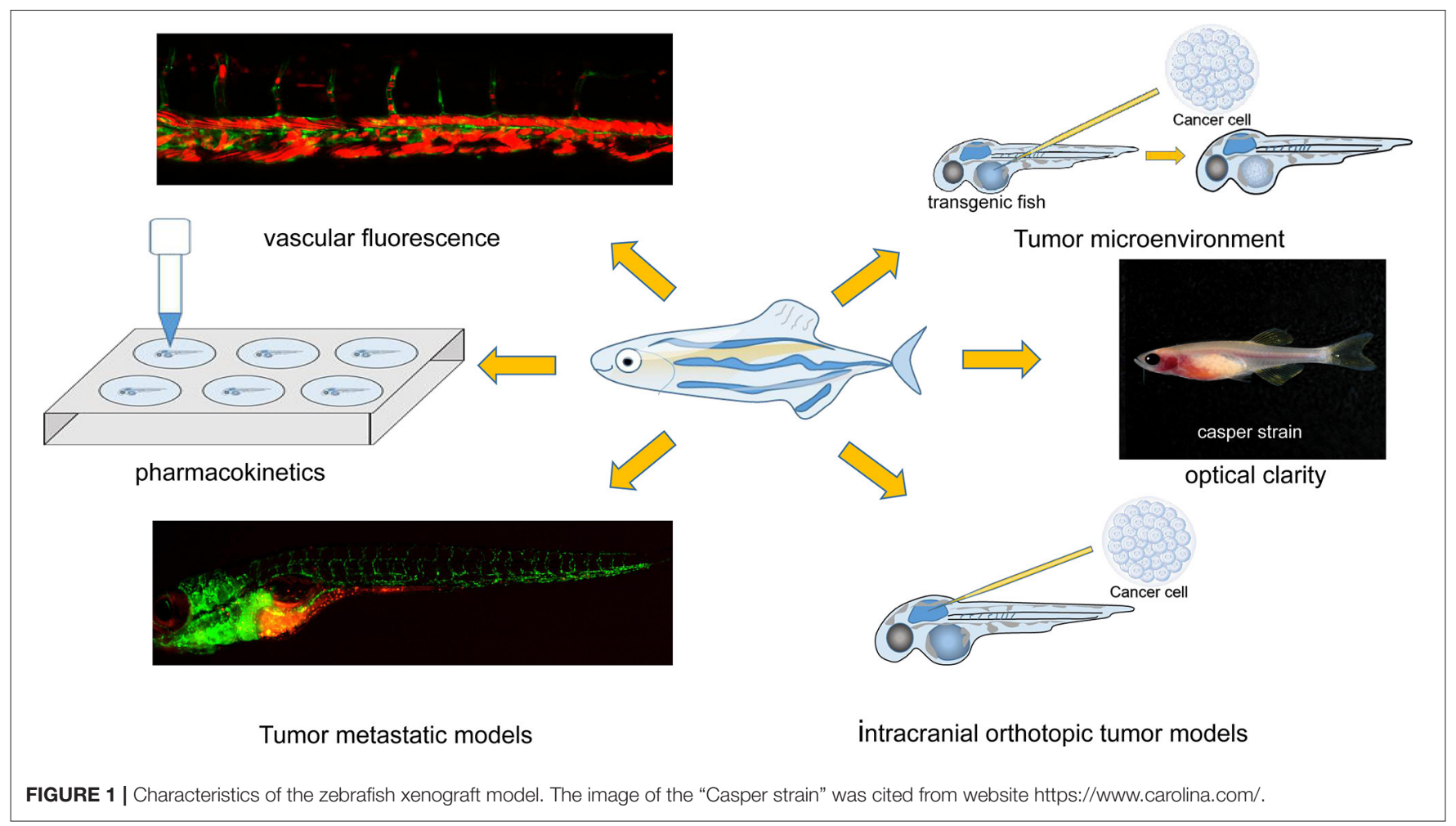

tract, and pancreas (Langenau et al., 2003, 2007; Ober et al., 2003; Patton et al., 2005; Sabaawy et al., 2006; Park et al., 2008; Lee et al., 2009; Gutierrez et al., 2011; Jung et al., 2011; Neumann et al., 2011; Rudner et al., 2011; Li et al., 2012; Nguyen et al., 2012). The orthotopic zebrafish tumor model has emerged in studies of multiple types of cancers, such as gastrointestinal tumors, glioblastoma, pancreatic cancer, retinoblastoma, and uveal melanoma (Marques et al., 2009; Lal et al., 2012; Jo et al., 2013; Rampazzo et al., 2013; van der Ent et al., 2014a, Chen et al., 2015; Eden et al., 2015; Hamilton et al., 2016; Jung et al., 2016; Vittori et al., 2016; Welker et al., 2016). Researchers have utilized zebrafish for the orthotopic transplantation of rhabdomyosarcoma to open new avenues for personalized therapy (Yan et al., 2019). The orthotopic tumor model can simulate real tumor conditions in humans; particularly, orthotopic models of brain tumors in zebrafish have been reported and will be further described. The applications of the zebrafish xenograft model are summarized in Table 1.

\section{THE ZEBRAFISH MODEL AS A METASTATIC AND INTRACRANIAL ORTHOTOPIC TOOL IN CANCER RESEARCH}

Tumor metastasis models and intracranial orthotopic tumor models are essential in cancer research. In this regard, the zebrafish tumor model can also mimic tumor development in the human body.
Cancer metastasis and recurrence remain the most significant threats to patients (Yan et al., 2019). For some particular cancer types, including uveal melanoma, Ewing's sarcoma and triplenegative breast cancer, the use of metastatic models is preferred over orthotopic models (Paulussen et al., 1998; Tomasin et al., 2019; Johansson et al., 2020). Once the clinical symptoms of these types of tumors, such as a palpable mass, arouse the patient's attention, distant metastases have likely already occurred (Paulussen et al., 1998; Tomasin et al., 2019; Johansson et al., 2020). Therefore, metastatic animal models need to be established to evaluate the ability of cancer cell migration and the efficacy of antitumor drugs.

\section{Tracking Cancer Cell Intravasation}

Currently, metastasis of human cancers is largely studied via transgenic and immunocompromised mPDX models, which are useful for measuring the end-point tumor volume but are unable to quantify or recapitulate in vivo invasion, intravasation, extravasation, or the secondary tumor growth of patient-derived cancer cells in real time (Morton and Houghton, 2007; Konantz et al., 2012; van der Ent et al., 2014b; Barriuso et al., 2015; Hill et al., 2018; Yan et al., 2019). The methods used to establish an mPDX metastasis model include cell injection into the tail vein, spleen, or left ventricle, but the key step of metastasis, cancer cell intravasation, cannot be simulated (Goddard et al., 2016; Lizardo and Sorensen, 2018). Zebrafish, however, can offer many advantages as a model system for studying the complex, multistep processes involved during spontaneous cancer metastasis (Fior et al., 2017; Follain et al., 2018; Hill et al., 2018; Wong et al., 2019). Implantation into the yolk sac, perivitelline space (PVS) and 
TABLE 1 | Application of the zebrafish xenograft model.

\begin{tabular}{|c|c|c|c|c|c|}
\hline The tumor source & Label & Injected object & Location of injection & $\begin{array}{l}\text { Detecting } \\
\text { instrumentation }\end{array}$ & Observed indicator \\
\hline $\begin{array}{l}\text { Patient-derived primary cells } \\
\text { Bentley et al. (2015), Lin et al. } \\
\text { (2016), Gaudenzi et al. (2017) } \\
\text { Fior et al. (2017) }\end{array}$ & $\begin{array}{l}\text { Fluorescent dye (such } \\
\text { as CM-Dil) Ghotra et al. } \\
\text { (2012), Wertman et al. } \\
\text { (2016) }\end{array}$ & $\begin{array}{l}\text { Adult zebrafish Tang } \\
\text { et al. (2014), Zhang } \\
\text { et al. (2018) }\end{array}$ & $\begin{array}{l}\text { Subcutaneous injection } \\
\text { Zhang et al. (2018) }\end{array}$ & $\begin{array}{l}\text { Confocal } \\
\text { microscopy/microscopy } \\
\text { (Pontes et al., 2017) }\end{array}$ & $\begin{array}{l}\text { Tumor proliferation (Fior } \\
\text { et al., 2017; Gamble } \\
\text { et al., 2018) }\end{array}$ \\
\hline $\begin{array}{l}\text { Laboratory human cell lines Lin } \\
\text { et al. (2019), Wong et al. (2019), } \\
\text { Smith et al. (2013), Chapman } \\
\text { et al. (2014), Haldi et al. (2006), } \\
\text { He et al. (2012), Corkery et al. } \\
\text { (2011), Marques et al. (2009), } \\
\text { Weiss et al. (2009), Latifi et al. } \\
\text { (2011), Zhao et al. (2009), Ghotra } \\
\text { et al. (2012), Vaughan et al. } \\
\text { (2015) }\end{array}$ & $\begin{array}{l}\text { Fluorescent protein } \\
\text { (such as GFP) Yan et al. } \\
\text { (2019) }\end{array}$ & $\begin{array}{l}\text { Embryonic zebrafish } \\
\text { (such as 48-hpf } \\
\text { embryos) Ghotra et al. } \\
\text { (2012), Pruvot et al. } \\
\text { (2011) }\end{array}$ & $\begin{array}{l}\text { Orthotopic injection } \\
\text { (such as brain) Vittori } \\
\text { et al. (2016), Lal et al. } \\
\text { (2012), Eden et al. } \\
\text { (2015), Wenger et al. } \\
\text { (2017), Banasavadi- } \\
\text { Siddegowda et al. } \\
\text { (2018), Gamble et al. } \\
\text { (2018), Casey et al. } \\
\text { (2017) }\end{array}$ & $\begin{array}{l}\text { Fluorescence } \\
\text { microscopy (Pruvot } \\
\text { et al., 2011; Ghotra } \\
\text { et al., 2012) }\end{array}$ & $\begin{array}{l}\text { Cell differentiation } \\
\text { (Rampazzo et al., 2013) }\end{array}$ \\
\hline \multirow[t]{6}{*}{$\begin{array}{l}\text { Laboratory zebrafish cell line } \\
\text { Zhang et al. (2018) }\end{array}$} & & & $\begin{array}{l}\text { Yolk sac Ghotra et al., } \\
\text { (2012), Letrado et al. } \\
\text { (2018), Wertman et al. } \\
\text { (2016) }\end{array}$ & $\begin{array}{l}\text { Histology (Welker et al., } \\
\text { 2016) }\end{array}$ & $\begin{array}{l}\text { Cell interaction (Wang } \\
\text { et al., 2015; Vazquez } \\
\text { Rodriguez et al., 2017; } \\
\text { Fornabaio et al., 2018; } \\
\text { Labernadie and Trepat, } \\
\text { 2018) }\end{array}$ \\
\hline & & & $\begin{array}{l}\text { Perivitelline space } \\
\text { Nicoli et al. (2007), van } \\
\text { der Ent et al. (2014a) }\end{array}$ & $\begin{array}{l}\text { BLI (bioluminescence } \\
\text { imaging) (Zhao et al., } \\
\text { 2009) }\end{array}$ & $\begin{array}{l}\text { Angiogenesis (Fior } \\
\text { et al., 2017; Gamble } \\
\text { et al., 2018) }\end{array}$ \\
\hline & & & & $\begin{array}{l}\text { MRI (magnetic } \\
\text { resonance imaging) } \\
\text { (White et al., 2008) }\end{array}$ & $\begin{array}{l}\text { Invasion/metastasis/ } \\
\text { adhesion (Ghotra et al., } \\
\text { 2012; Konantz et al., } \\
\text { 2012; Follain et al., } \\
\text { 2018; Gamble et al., } \\
\text { 2018; Fenizia et al., } \\
\text { 2019) }\end{array}$ \\
\hline & & & & $\begin{array}{l}\text { PET imaging (positron } \\
\text { emission tomography) } \\
\text { (White et al., 2008) }\end{array}$ & $\begin{array}{l}\text { Cell status (Yan et al., } \\
\text { 2019) }\end{array}$ \\
\hline & & & & $\begin{array}{l}\text { Ultrasound microscopy } \\
\text { (Goessling et al., 2007) }\end{array}$ & $\begin{array}{l}\text { Fluorescently labeled } \\
\text { nanoparticles/ } \\
\text { biodistribution (Sieber } \\
\text { et al., 2017; Chen } \\
\text { et al., 2019) }\end{array}$ \\
\hline & & & & $\begin{array}{l}\text { Epifluorescence } \\
\text { imaging (Dumartin } \\
\text { et al., 2011) }\end{array}$ & $\begin{array}{l}\text { Hemodynamic status } \\
\text { (Follain et al., 2018) }\end{array}$ \\
\hline
\end{tabular}

subcutaneous tissues allow the direct injection of cancer cells into the zebrafish's body (Abercrombie and Ambrose, 1958; Pruvot et al., 2011; Canella et al., 2017; Letrado et al., 2018). The yolk sac implantation method is more often used by researchers because it is a practical method that accommodates more cells (Wertman et al., 2016; Letrado et al., 2018). For example, by employing in vivo imaging coupled with $3 \mathrm{D}$ reconstruction and time-lapse microscopy, researchers can monitor interactions between cancer cells and the external surface of zebrafish vessels and record the process of tumor cells migrating along the vascular tubules in addition to morphological changes during the process (Fornabaio et al., 2018). Similarly, the zebrafish model can be used to research the morphological characteristics of tumor cells and the interactions between tumor cells and other cells (Vazquez Rodriguez et al., 2017; Labernadie and Trepat, 2018). However, the primary limitation of this method is that the yolk sac is composed of bulk proteins or lipids that differ from those of the patient's tumor microenvironment and that affect the phenotype and survival of tumor cells (Canella et al., 2017; Sant and TimmeLaragy, 2018). Comparatively, subcutaneous injection in the PVS provides a more beneficial tumor microenvironment for tumor implantation, cell survival, angiogenesis and metastasis (Zhao et al., 2011a; Fior et al., 2017; Costa et al., 2020b).

\section{Relationship Between Hemodynamics and Metastasis}

By using an easy-to-use angiographic zebrafish model, researchers can illuminate the relationship between hemodynamics and tumor formation via circulating tumor cells (CTCs). In the zebrafish model, researchers have found that 
blood flow is essential for endothelial remodeling and subsequent prometastatic extravasation, even though slow blood flow allows the arrest and adhesion of CTCs. Furthermore, researchers have observed that laminar flow is conducive to the arrest of CTCs and stimulates endothelial remodeling. The same report also suggested that the key to successfully treating metastatic tumors is interfering with endothelial remodeling (Follain et al., 2018). It is worth noting that individual cancer cells can be dynamically visualized in the zPDX model, especially during metastasis (Hill et al., 2018; Astell and Sieger, 2019; Yan et al., 2019).

\section{Monitoring the Behavior of Single Cancer Cells in Metastasis}

Patient-derived tumors have higher heterogeneity than do laboratory-stable tumor cell lines (Fior et al., 2017). Furthermore, patient-derived cancer cells possess certain properties of stem cells that laboratory tumor cell lines do not always offer, including those derived from Wilms' tumor, rhabdomyosarcoma and osteosarcoma (Hirschmann-Jax et al., 2004). It is necessary to study the behavior of a single cancer cell; however, to date, the visualization of a single cancer cell in the MPDX model remains highly challenging and requires a complex, accurate, multistep operation process to successfully implement (Ellenbroek and van Rheenen, 2014). Using confocal microscopy, studies can dynamically observe and record the single-cell behavior of cancer cells either expressing GFP or labeled with a fluorochrome (Follain et al., 2018; Hill et al., 2018; Shi et al., 2019; Yan et al., 2019). For instance, researchers analyzed the behavior of a single cancer cell in vivo in a zPDX model and concluded that rhabdomyosarcoma (RMS) cells are composed of three cancer cell types: (1) highly migratory cells, (2) actively proliferating cells, and (3) bystander cells (Ignatius et al., 2012, 2017; Yan et al., 2019). Confocal microscopy can also be used to observe self-renewal, cell-state transitions, regeneration and the other hallmarks of cancer at the single-cell level in the xenograft setting (Moore et al., 2016). Furthermore, the $\mathrm{Tg}$ (fli:eGFP) zebrafish line with GFP-labeled vasculature allows the direct study of the relationship of vascular endothelial cells with cancer cell intravasation and extravasation and accurately identify the position of the cancer cells (Weiss et al., 2009; Gill et al., 2010).

\section{Evaluation of The Metastatic Ability of a Cell Line in vivo}

To test whether the expression of different genes in tumor cells affects metastasis in vivo, we need an animal model in which tumors easily metastasize. For example, using an embryonic zebrafish model, researchers have verified that upregulated CD133 expression causes BAK-R cells to be more invasive and metastatic than BAK-P cells (Simbulan-Rosenthal et al., 2019).

The advantages of the zebrafish model are shown not only when studying tumor metastasis but also when establishing orthotopic intracranial tumors. From an structural point of view, the brain morphology in zebrafish is similar to that in humans. Zebrafish also have brain structures that are homologous to those of humans, such as the optic tectum, thalamus and cerebellum (Guo, 2009). However, in contrast to humans, zebrafish manifest equivalent parts of the brain stem in the most dorsal positions of the telencephalon (Wullimann and Mueller, 2004; Leung et al., 2013; Smith et al., 2013). Hence, orthotopically transplanted tumors at this position can be easily established with less damage to cerebral tissue in the zebrafish model (Lal et al., 2012; Eden et al., 2015; Vittori et al., 2016; Casey et al., 2017; Wenger et al., 2017; Banasavadi-Siddegowda et al., 2018; Gamble et al., 2018). Additionally, the blood-brain barrier (BBB) is a specialized tissue originating from brain capillaries that restricts the flow of various molecules, drugs and cells into and out of the brain (Levin et al., 1984, 2015; Neuwelt, 2004; Banks, 2009; Abbott et al., 2010; Krueger and Bechmann, 2010; Ago and Kitazono, 2014; Attwell et al., 2016; Moore et al., 2016). It has been reported that the $\mathrm{BBB}$ of zebrafish and mammals are highly similar with regard to formation and function (Jeong et al., 2008; Kulkarni et al., 2014; Moore et al., 2016); therefore, researchers can simulate and observe the process of cancer cell metastasis across the BBB in the zPDX model and explore the mechanism(s) involved (Tanner, 2018).

\section{THE ZEBRAFISH MODEL IN ANTICANCER THERAPY STUDIES}

The zebrafish model has been widely adopted as an emerging anticancer screening platform. Its distinguishing features include rapid turnaround, small space requirements, small sample size requirements, low doses of screened drug, and highthroughput capability (Veinotte et al., 2014; Hamilton et al., 2018; Cornet et al., 2019; Cully, 2019; Hason and Bartuněk, 2019; Yang et al., 2019). Although many zebrafish can be produced after a single spawning event, they can be numbered and tracked individually, which makes the experimental results more accurate. Additionally, since the zebrafish model is prone to metastasis, we can also observe the inhibitory effect of therapy on tumor metastasis during drug screening.

Despite the widespread use of mouse models, researchers have found a minor shortcoming of mouse models of implanted tumors: pharmacokinetics. Rapid liver clearance in mice fails to maintain a stable blood drug concentration and prevents us from adequately assessing drug efficacy (Frapolli et al., 2006; Stuurman et al., 2013; Herbrink et al., 2015). However, the zebrafish model compensates for this limitation. For example, a previous study revealed that adipocytes increase the proliferation and invasion of adjacent melanoma cells. Upon directly injecting lipofermata, which abrogates lipid transport into melanoma cells, into tumor tissue in a zebrafish model, researchers observed a significant decrease in melanoma growth (Zhang et al., 2018). This process was accompanied by an obvious decrease in the lipid content of medically treated tumors, which confirms that lipofermata is effective without undergoing rapid liver clearance (Zhang et al., 2018).

The reason why zebrafish can serve as an ideal model for pharmacokinetic studies is their habitat. Zebrafish live in water and can rapidly absorb chemicals from the aqueous environment across the gills and buccal cavity. Drug screening is easy because researchers can directly add the drug to the water (Lieschke and 
Currie, 2007; Wang et al., 2010; Wu et al., 2017; Garcia-Caballero et al., 2018). This method has the following pharmacokinetic advantages: (1). the drug concentration in vivo in zebrafish can be continuously replenished in the aqueous environment; and (2). drugs in water can penetrate into subcutaneously implanted tumors (Zhang et al., 2015; Garcia-Caballero et al., 2018).

Currently, nanocarriers containing antitumor drugs have become a research focus because prolonging blood drug concentrations increases drug efficacy and decreases adverse drug effects via enhanced permeability and retention effects (EPRs) in solid tumors. Hence, the optimization of pharmacokinetics and biodistribution plays an essential role in the efficacy of nanomedicines. Zebrafish, as a nanomaterial drug delivery system screening tool, presents unique advantages such as a high level of genetic homology to humans, availability of transgenic lines and, most importantly, optical transparency (Lieschke and Currie, 2007; Delvecchio et al., 2011; Sieber et al., 2017). For example, transgenic zebrafish lines that selectively express fluorescent proteins in specific tissues, such as the vasculature, liver and spleen, allow the observation of the biodistribution of fluorescently labeled nanoparticles and the exploration of the circulatory behavior of nanoparticulate drug delivery systems (Gong et al., 2013; Evensen et al., 2016). These zebrafish strains can also allow researchers to directly observe the tumor-targeting effect of the drug. For example, zebrafish xenografts have been chosen as a rapid screening platform for testing the efficacy of monoclonal antibodies in cancer therapy, such as cetuximab and bevacizumab. The result indicates a similar behavioral response to therapies in patients as in zPDXs. It has been suggested that zebrafish xenografts are a promising in vivo screening platform for precision medicine (Fior et al., 2017; Rebelo de Almeida et al., 2020). As mentioned above, zebrafish provide a useful model to study the restrictive ability and permeability of the BBB (O'Brown et al., 2019). In the same manner, researchers can observe and explore the encephalic distribution and concentration of anticancer drugs to provide a basis for the treatment of intracranial tumors (Zeng et al., 2017). Researchers can also directly quantitatively evaluate the toxic effects of antitumor drugs in the zebrafish model (Raeber et al., 2005; Fisher, 2011; Junttila and de Sauvage, 2013; Damhofer et al., 2015; Cavalloni et al., 2016; Qin et al., 2016). For example, embryonic death and abnormal phenotypes such as pericardial edema, retarded swim bladder inflation, spinal curvature, short body length, and other adverse effects of drugs can be directly observed only via optical microscopy (Gutiérrez-Lovera et al., 2019; Lin et al., 2019; Vicente et al., 2020). Small-molecule inhibitors can block message transmission in cancer cells and influence tumor behavior and be taken up by zebrafish in the aqueous environment (Konantz et al., 2019). Interestingly, using the zebrafish model, we can screen many compounds and identify chemicals that inhibit tumor growth and development. In addition, we can acquire circulating blood from adult zebrafish via cardiac puncture and measure the serum drug concentration by mass spectrometry (Yan et al., 2019). We can thus establish a correlation between the serum drug concentration in zebrafish and the specific effective drug concentration of patients. However, different drugs have different solubilities in water and absorptive characteristics into fish from water. Therefore, some drugs that are more hydrophobic can be dissolved in water by either promoting solvents or combining the drugs with nanomaterials (Wang et al., 2010; Evensen et al., 2016; Li et al., 2017; Sieber et al., 2017; Garcia-Caballero et al., 2018). Even some protein-based drugs or nanodrug carriers can be injected directly into the blood circulation via microinjection (Evensen et al., 2016; Wu et al., 2017, 2020).

In addition to its use in conventional drug screening, the zebrafish model is being applied to evaluate the effectiveness of radiotherapy (Gnosa et al., 2016; Costa et al., 2020a). Furthermore, zebrafish can be used with fluorescent labeling to experimentally confirm that various carriers, such as bacteria (which enhance antitumor effects) can be absorbed into the body (Xie et al., 2018; Chen et al., 2019; Shi et al., 2019). For instance, researchers marked cancer cells with Dir and labeled Escherichia coli strain Nissle 1917 (EcN) with GFP, and using confocal laser scanning microscopy, we could visually identify the relative position of $\mathrm{EcN}$ in the zebrafish tumor model (Shi et al., 2019).

\section{THE ZEBRAFISH MODEL IN STUDIES OF THE TUMOR MICROENVIRONMENT}

The tumor microenvironment plays an essential role in tumor formation, growth, metastasis and development (Chapman et al., 2014; Astell and Sieger, 2019; de Oliveira et al., 2019; Giallongo et al., 2019; Gómez-Abenza et al., 2019; Liu et al., 2019; Sun et al., 2019). Zebrafish, as a tumor model, are becoming increasingly prominent in studying the tumor microenvironment (Liu and Leach, 2011; Wang et al., 2015; Liu et al., 2017, 2019; Astell and Sieger, 2019; Giallongo et al., 2019; Gómez-Abenza et al., 2019; Sun et al., 2019). First, cancer cells can be implanted into different positions in zebrafish that provide distinct tumor microenvironments. Another example shows that, using a plin2tdTomato transgenic line that shows the location of the deposits of subcutaneous fat, researchers can identify different zebrafish anatomy positions with distinct adipocyte fat pad contents (Zhang et al., 2018). Other groups transplanted a melanoma cell line into the ventral and dorsal subcutaneous fat pads of fish and verified the effect of adipocytes on melanoma metastasis (Zhang et al., 2018). In another study, investigators successfully injected three human liver cancer cell lines into the yolk sac of $a c h e^{-/-}$zebrafish and found that acetylcholine, one of the molecules found in the tumor microenvironment, facilitates cancer cell growth (Avci et al., 2018). In another experiment on tumor cells implanted into the yolk sac, researchers discovered that the hypoxic environment of the yolk sac may simulate the tumor microenvironment of some human tumors due to the lack of vascularization. They further found that the proliferation of primary effusion lymphoma cells in xenografts requires a hypoxic environment to stimulate eukaryotic translation initiation factor 4E2 (elF4E2) (Pringle et al., 2019).

Transgenic zebrafish lines in which the expression of a specific gene is inhibited or overexpressed can also be used to study the tumor microenvironment (Figure 2) (Bedell et al., 2012; Jao et al., 2013; Irion et al., 2014; Sung et al., 2014; Kim et al., 


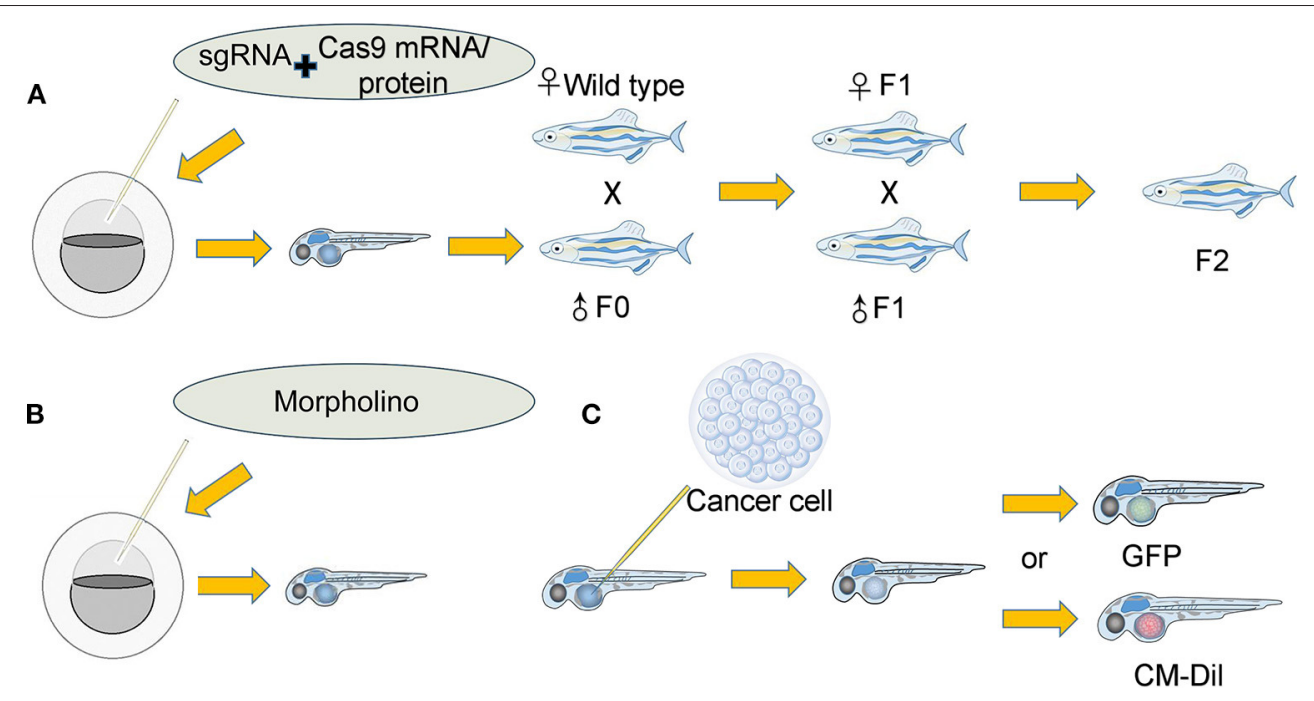

FIGURE 2 | Establishment of the tumor microenvironment in the zebrafish xenograft model. (A): (I) A single-guide RNA (sgRNA) was coinjected along with Cas9 mRNA/protein into either the yolk or cell of single-cell stage embryos. The coinjected embryos grew into founder fish. (II) The founder fish were then outcrossed to wild-type siblings to generate heterozygous F1 fish. Fish lacking the correct genotype (as identified by fluorescence PCR and sequencing) were eliminated. (III) The F1 fish carrying the correct mutations were then crossed to generate F2 progeny. F2 offspring will provide an optimal tumor microenvironment for researchers. (B): Morpholino knockdown of specific genes in zebrafish embryos directly provides the tumor microenvironment. (C): (I) Cancer cells that were either expressing GFP or labeled with other fluorescent dyes were implanted into zebrafish. (II) Various indexes of cancer cells were observed and recorded.

2017) by providing a unique tumor microenvironment and to further explore the relationship between tumor development and the tumor microenvironment (Figure 2). The premise is that the gene signaling we explore is conserved between zebrafish and humans. There is a strong advantage in the zebrafish model because the zebrafish genome was revealed to have exceedingly high homology with the human genome (Burgess, 2013; Howe et al., 2013). For instance, researchers discovered that zebrafish cxcr4 $(c x c r 4 b)$ is highly expressed in neutrophils and controls neutrophil number and motility and that neutrophils interact with cancer cells to initiate early metastatic events. MDA-MB-231-B breast tumor cells were injected into the circulation of wild-type zebrafish and $\mathrm{cxcr} 4 \mathrm{~b}^{-/-}$ zebrafish embryos at $2 \mathrm{dpf}$. The researchers found that the tumor cells in $c x c r 4 b^{-/-}$zebrafish embryos did not influence neutrophil speed or distance traveled relative to wild-type siblings. In this experiment, GFP-labeled neutrophils were easily detected via confocal microscopy. In conclusion, researchers have proposed that $c x c r 4 b$ signaling supports interactions between neutrophils and tumor cells and drives early tumor metastasis (Tulotta et al., 2019). In another experiment, liver cancer cells implanted into ache $e^{-1-}$ mutant zebrafish exhibited stronger growth and metastasis abilities than those implanted into wild-type siblings (Avci et al., 2018). Additionally, glioma cells implanted into irf $8^{-/-}$transgenic zebrafish that lack microglia and wildtype zebrafish treated with CSF-1 inhibitor (a pharmacological means of decreasing microglia) have demonstrated a unique role for zebrafish microglia in facilitating human glioma cell growth (Hamilton et al., 2016). Similarly, researchers separately created CRISPR-mutant zebrafish in which the function of EDN3 or ECE2 in the tumor microenvironment was lost, with both mutations exerting a severe effect on melanocyte development. Then, researchers transplanted melanoma cells into wild-type, EDN3-, or ECE2-deficient transgenic zebrafish and verified that variation in the tumor microenvironment exerts a tremendous impact on melanoma development and metastasis (Kim et al., 2017). The tumor microenvironment is established by a change in gene expression in the short term but can also affect tumor behaviors. Morpholino injection is also a method used to alter gene expression (Figure 2) (Gamble et al., 2018). Using this method, researchers found that the change in laminin alpha 5 expression in the tumor microenvironment influenced glioblastoma microtumor formation and invasion (Gamble et al., 2018). The tumor microenvironment provided by the zebrafish model possesses a unique advantage.

The tumor immune microenvironment is also critical in cancer development and metastasis. Similar to humans, zebrafish also have a generally defined immune system (Lam et al., 2002; Danilova et al., 2004; Langenau et al., 2004; Langenau and Zon, 2005; Giallongo et al., 2016; de Oliveira Mann et al., 2019). By exploiting this characteristic, scientists showed that mesenchymal stromal cells are involved in the tumor immune microenvironment transformation of multiple myeloma (Giallongo et al., 2019). The innate immune microenvironment includes not only the neutrophils mentioned above but also macrophages. Some research groups generated a $m y d 88^{\mathrm{w} 187}$ mutant and pu.1/spilb $b^{\text {fh509 }}$ mutant zebrafish strain, which affect the number and function of macrophages, respectively, in the zebrafish body (Roh-Johnson et al., 2017). It was further demonstrated that macrophages transfer cytoplasm to tumor cells and that this transfer correlates with 
increased tumor cell dissemination in vivo (Roh-Johnson et al., 2017).

\section{DISCUSSIONS AND FUTURE PERSPECTIVES}

The optical clarity of zebrafish allows us to accurately observe the shape and size of a tumor, the movement and morphology of a single cell of the tumor, interactions between cells, and various physical indicators related to tumor growth. Transgenic zebrafish with vascular-specific fluorescence allow the observation of tumor neovascularization, which is an important condition for tumor development. Zebrafish models of tumor metastasis and intracranial orthotopic tumors as well their unique pharmacokinetics compensate for the limitations of tumor models in mice. The unique zebrafish tumor microenvironment and changes in the expression of certain genes provide an emerging and useful animal model for studying the effect and mechanism of the tumor microenvironment on tumor cells in vivo. These features of the zebrafish tumor model should be innovatively applied to tumor research. The tumor-targeting ability of drugs and the in vivo biodistribution of a drug are always the focuses of anticancer drug research. Optical transparency and easy real-time monitoring make zebrafish an ideal model organism for observing the distribution of a drug. Additionally, the switch of metastatic phenotypes is also observed when the tumor microenvironment changes. For instance, by moving cancer cells to more restrictive tumor microenvironments, we observed that breast cancer cells switched from a metastatic phenotype, which depends on integrin adhesion and actin polymerization, to a tubulindependent metastatic phenotype (Balzer et al., 2012; Stroka and Konstantopoulos, 2014). This implies that the physical properties of the cellular microenvironment, such as the proportions of matrix constituents, concentration of matrix proteins or levels of cytokines, can induce switching between migratory phenotypes (Stuelten et al., 2018). The zebrafish model, which offers a direct visual model of metastasis, may help answer some questions, such as which cellular or microenvironmental parameters trigger transformation and the results of switching migratory phenotypes (Stuelten et al., 2018).

One future direction in the use of zebrafish as a model organism of tumor growth and progression is to better mimic

\section{REFERENCES}

Abbott, N. J., Patabendige, A. A., Dolman, D. E., Yusof, S. R., and Begley, D. J. (2010). Structure and function of the blood-brain barrier. Neurobiol. Dis. 37, 13-25. doi: 10.1016/j.nbd.2009.07.030

Abercrombie, M., and Ambrose, E. J. (1958). Interference microscope studies of cell contacts in tissue culture. Exp. Cell Res. 15, 332-345. doi: 10.1016/0014-4827(58)90034-X

Ago, T., and Kitazono, T. (2014). [Brain pericyte in health and cerebrovascular diseases]. Fukuoka Igaku Zasshi. 105, 125-130.

Astell, K. R., and Sieger, D. (2019). Zebrafish in vivo models of cancer and metastasis. Cold Spring Harb. Perspect. Med. 10:a037077. doi: $10.1101 /$ cshperspect.a037077 the tumor environment of the human body. An interesting study reported the generation of mouse-zebrafish hematopoietic tissuederived chimeric embryos (Parada-Kusz et al., 2018). This finding implies that we are likely to reconstruct a more human-like tumor microenvironment in the zebrafish model (Vinothkumar et al., 2019). There are still many needs to be addressed in studies of the tumor immune microenvironment, such as the adaptive immune microenvironment. Although zebrafish possess regenerative abilities, spinal cord injury may lead to massive losses of innate immune cells (Tsarouchas et al., 2018). Hence, when we complete the microinjections, we should exclude zebrafish with spinal damage.

With the development and application of robotics to inject zebrafish embryos, the limitation of inconsistencies when generating models has been addressed (Spaink et al., 2013). Although the issue of temperature differences between the xenograft and host was not addressed, there were studies reporting $34-35^{\circ} \mathrm{C}$ as a compromise allowing growth of both human cancer cells and fish (Haldi et al., 2006; Nicoli et al., 2007; Smith et al., 2013; Bentley et al., 2015; Fazio et al., 2020). These difficulties, including inconsistencies in protocols between different laboratories and a lack of reproducibility, also limit the widespread use of zebrafish. To overcome these limitations, it is necessary to strengthen the contact and information sharing between labs. In conclusion, although no model is perfect, the zebrafish model has unique advantages and even plays an irreplaceable role in some respects.

\section{AUTHOR CONTRIBUTIONS}

RJ concepted and designed the review. XC and YL drafted the manuscript. TY drawn the figures. All the authors participated in writing and final approval of the manuscript and are responsible for all aspects of the work.

\section{FUNDING}

This research was supported by the Science and Technology Commission of Shanghai (20DZ2270800), the National Natural Science Foundation of China (grants 81770961 and 82073889), and the Science and Technology Commission of Shanghai (19JC1410200). The funders played no role in the study design, data collection and analysis, decision to publish, or preparation of the manuscript.

Attwell, D., Mishra, A., Hall, C. N., O’Farrell, F. M., and Dalkara, T. (2016). What is a pericyte? J. Cereb. Blood Flow Metab. 36, 451-455. doi: 10.1177/0271678X15610340

Avci, M. E., Keskus, A. G., Targen, S., Isilak, M. E., Ozturk, M., Atalay, R. C., et al. (2018). Development of a novel zebrafish xenograft model in ache mutants using liver cancer cell lines. Sci. Rep. 8:1570. doi: 10.1038/s41598-01819817-w

Balzer, E. M., Tong, Z., Paul, C. D., Hung, W. C., Stroka, K. M., Boggs, A. E., et al. (2012). Physical confinement alters tumor cell adhesion and migration phenotypes. FASEB J. 26, 4045-4056. doi: 10.1096/fj.12-211441

Banasavadi-Siddegowda, Y. K., Welker, A. M., An, M., Yang, X., Zhou, W., Shi, G., et al. (2018). PRMT5 as a druggable target for glioblastoma therapy. Neuro-oncology 20, 753-763. doi: 10.1093/neuonc/nox206 
Banks, W. A. (2009). Characteristics of compounds that cross the blood-brain barrier. BMC Neurol. 9(Suppl 1):S3. doi: 10.1186/1471-2377-9-S1-S3

Barriuso, J., Nagaraju, R., and Hurlstone, A. (2015). Zebrafish: a new companion for translational research in oncology. Clin. Cancer Res. 21, 969-975. doi: 10.1158/1078-0432.CCR-14-2921

Barros, T. P., Alderton, W. K., Reynolds, H. M., Roach, A. G., and Berghmans, S. (2008). Zebrafish: an emerging technology for in vivo pharmacological assessment to identify potential safety liabilities in early drug discovery. $\mathrm{Br}$. J. Pharmacol. 154, 1400-1413. doi: 10.1038/bjp.2008.249

Bedell, V. M., Wang, Y., Campbell, J. M., Poshusta, T. L., Starker, C. G., Krug, R. G. II, et al. (2012). In vivo genome editing using a high-efficiency TALEN system. Nature 491, 114-118. doi: 10.1038/nature11537

Bentley, V. L., Veinotte, C. J., Corkery, D. P., Pinder, J. B., LeBlanc, M. A., Bedard, K., et al. (2015). Focused chemical genomics using zebrafish xenotransplantation as a pre-clinical therapeutic platform for T-cell acute lymphoblastic leukemia. Haematologica 100, 70-76. doi: 10.3324/haematol.2014.110742

Bergers, G., Javaherian, K., Lo, K. M., Folkman, J., and Hanahan, D. (1999). Effects of angiogenesis inhibitors on multistage carcinogenesis in mice. Science 284, 808-812. doi: 10.1126/science.284.5415.808

Blackburn, J. S., Liu, S., Raiser, D. M., Martinez, S. A., Feng, H., Meeker, N. D., et al. (2012). Notch signaling expands a pre-malignant pool of T-cell acute lymphoblastic leukemia clones without affecting leukemia-propagating cell frequency. Leukemia 26, 2069-2078. doi: 10.1038/leu.2012.116

Britto, D. D., Hall, C. J., and Astin, J. W. (2019). In vivo imaging and quantitation of the host angiogenic response in zebrafish tumor xenografts. J. Vis. Exp. e59849. doi: $10.3791 / 59849$

Britto, D. D., Wyroba, B., Chen, W., Lockwood, R. A., Tran, K. B., Shepherd, P. R., et al. (2018). Macrophages enhance Vegfa-driven angiogenesis in an embryonic zebrafish tumour xenograft model. Dis. Model. Mech. 11:dmm035998. doi: $10.1242 / \mathrm{dmm} .035998$

Burgess, D. J. (2013). Genomics: new zebrafish genome resources. Nat. Rev. Genet. 14, 368-369. doi: $10.1038 / \mathrm{nrg} 3500$

Canella, A., Welker, A. M., Yoo, J. Y., Xu, J., Abas, F. S., Kesanakurti, D., et al. (2017). Efficacy of onalespib, a long-acting secondgeneration HSP90 Inhibitor, as a single agent and in combination with temozolomide against malignant gliomas. Clin. Cancer Res. 23, 6215-6226. doi: 10.1158/1078-0432.CCR-16-3151

Casey, M. J., Modzelewska, K., Anderson, D., Goodman, J., Boer, E. F., Jimenez, L., et al. (2017). Transplantation of zebrafish pediatric brain tumors into immunecompetent hosts for long-term study of tumor cell behavior and drug response. J. Vis. Exp. e55712. doi: 10.3791/55712

Cavalloni, G., Peraldo-Neia, C., Varamo, C., Casorzo, L., Dell'Aglio, C., Bernabei, P., et al. (2016). Establishment and characterization of a human intrahepatic cholangiocarcinoma cell line derived from an Italian patient. Tumour Biol. 37, 4041-4052. doi: 10.1007/s13277-015-4215-3

Chapman, A., Fernandez del Ama, L., Ferguson, J., Kamarashev, J., Wellbrock, C., and Hurlstone, A. (2014). Heterogeneous tumor subpopulations cooperate to drive invasion. Cell Rep. 8, 688-695. doi: 10.1016/j.celrep.2014.06.045

Chen, E. Y., DeRan, M. T., Ignatius, M. S., Grandinetti, K. B., Clagg, R., McCarthy, K. M., et al. (2014). Glycogen synthase kinase 3 inhibitors induce the canonical WNT/beta-catenin pathway to suppress growth and self-renewal in embryonal rhabdomyosarcoma. Proc. Natl. Acad. Sci. U.S.A. 111, 5349-5354. doi: $10.1073 /$ pnas. 1317731111

Chen, J. N., and Fishman, M. C. (1996). Zebrafish tinman homolog demarcates the heart field and initiates myocardial differentiation. Development 122, 3809-3816.

Chen, X., Wang, J., Cao, Z., Hosaka, K., Jensen, L., Yang, H., et al. (2015). Invasiveness and metastasis of retinoblastoma in an orthotopic zebrafish tumor model. Sci. Rep. 5:10351. doi: 10.1038/srep10351

Chen, Y., Liu, W., Shang, Y., Cao, P., Cui, J., Li, Z., et al. (2019). Folic acidnanoscale gadolinium-porphyrin metal-organic frameworks: fluorescence and magnetic resonance dual-modality imaging and photodynamic therapy in hepatocellular carcinoma. Int. J. Nanomed. 14, 57-74. doi: 10.2147/IJN.S177880

Chiavacci, E., Rizzo, M., Pitto, L., Patella, F., Evangelista, M., Mariani, L., et al. (2015). The zebrafish/tumor xenograft angiogenesis assay as a tool for screening anti-angiogenic miRNAs. Cytotechnology 67, 969-975. doi: $10.1007 /$ s10616-014-9735-y
Cho, S. J., Kook, M. C., Lee, J. H., Shin, J. Y., Park, J., Bae, Y. K., et al. (2015). Peroxisome proliferator-activated receptor gamma upregulates galectin- 9 and predicts prognosis in intestinal-type gastric cancer. Int. J. Cancer. 136, 810-820. doi: 10.1002/ijc.29056

Chung, A. S., Lee, J., and Ferrara, N. (2010). Targeting the tumour vasculature: insights from physiological angiogenesis. Nat. Rev. Cancer 10, 505-514. doi: $10.1038 / \mathrm{nrc} 2868$

Cirello, V., Gaudenzi, G., Grassi, E. S., Colombo, C., Vicentini, L., Ferrero, S., et al. (2018). Tumor and normal thyroid spheroids: from tissues to zebrafish. Minerva Endocrinol. 43, 1-10. doi: 10.23736/S0391-1977.17.02610-4

Corkery, D. P., Dellaire, G., and Berman, J. N. (2011). Leukaemia xenotransplantation in zebrafish-chemotherapy response assay in vivo. Br. J. Haematol. 153, 786-789. doi: 10.1111/j.1365-2141.2011.08661.x

Cornet, C., Dyballa, S., Terriente, J., and Di Giacomo, V. (2019). ZeOncoTest: refining and automating the zebrafish xenograft model for drug discovery in cancer. Pharmaceuticals 13:1. doi: 10.3390/ph13010001

Costa, B., Estrada, M. F., Mendes, R. V., and Fior, R. (2020a). Zebrafish avatars towards personalized medicine-a comparative review between avatar models. Cells 9:293. doi: 10.3390/cells9020293

Costa, B., Ferreira, S., Povoa, V., Cardoso, M. J., Vieira, S., Stroom, J., et al. (2020b). Developments in zebrafish avatars as radiotherapy sensitivity reporters - towards personalized medicine. EBioMedicine 51:102578. doi: 10.1016/j.ebiom.2019.11.039

Cully, M. (2019). Zebrafish earn their drug discovery stripes. Nat. Rev. Drug Discov. 18, 811-813. doi: 10.1038/d41573-019-00165-x

D’Agati, G., Beltre, R., Sessa, A., Burger, A., Zhou, Y., Mosimann, C., et al. (2017). A defect in the mitochondrial protein Mpv17 underlies the transparent casper zebrafish. Dev. Biol. 430, 11-17. doi: 10.1016/j.ydbio.2017.07.017

Damhofer, H., Ebbing, E. A., Steins, A., Welling, L., Tol, J. A., Krishnadath, K. K., et al. (2015). Establishment of patient-derived xenograft models and cell lines for malignancies of the upper gastrointestinal tract. J. Transl. Med. 13:115. doi: 10.1186/s12967-015-0469-1

Danilova, N., Hohman, V. S., Sacher, F., Ota, T., Willett, C. E., and Steiner, L. A. (2004). T cells and the thymus in developing zebrafish. Dev. Comp. Immunol. 28, 755-767. doi: 10.1016/j.dci.2003.12.003

de Oliveira Mann, C. C., Orzalli, M. H., King, D. S., Kagan, J. C., Lee, A. S. Y., and Kranzusch, P. J. (2019). Modular Architecture of the STING C-Terminal Tail Allows Interferon and NF- $\mathrm{BB}$ Signaling Adaptation. Cell Rep. 27, 1165-1175.e1165. doi: 10.1016/j.celrep.2019. 03.098

de Oliveira, S., Houseright, R. A., Graves, A. L., Golenberg, N., Korte, B. G., Miskolci, V., et al. (2019). Metformin modulates innate immune-mediated inflammation and early progression of NAFLD-associated hepatocellular carcinoma in zebrafish. J. Hepatol. 70, 710-721. doi: 10.1016/j.jhep.2018. 11.034

Delvecchio, C., Tiefenbach, J., and Krause, H. M. (2011). The zebrafish: a powerful platform for in vivo, HTS drug discovery. Assay Drug Dev. Technol. 9, 354-361. doi: $10.1089 /$ adt.2010.0346

Drabsch, Y., Snaar-Jagalska, B. E., and Ten Dijke, P. (2017). Fish tales: the use of zebrafish xenograft human cancer cell models. Histol. Histopathol. 32, 673-686. doi: 10.14670/HH-11-853

Dumartin, L., Whiteman, H. J., Weeks, M. E., Hariharan, D., Dmitrovic, B., Iacobuzio-Donahue, C. A., et al. (2011). AGR2 is a novel surface antigen that promotes the dissemination of pancreatic cancer cells through regulation of cathepsins B and D. Cancer Res. 71, 7091-7102. doi: 10.1158/0008-5472.CAN-11-1367

Eden, C. J., Ju, B., Murugesan, M., Phoenix, T. N., Nimmervoll, B., Tong, Y., et al. (2015). Orthotopic models of pediatric brain tumors in zebrafish. Oncogene 34, 1736-1742. doi: 10.1038/onc.2014.107

Eguiara, A., Holgado, O., Beloqui, I., Abalde, L., Sanchez, Y., Callol, C., et al. (2011). Xenografts in zebrafish embryos as a rapid functional assay for breast cancer stem-like cell identification. Cell Cycle 10, 3751-3757. doi: $10.4161 /$ cc. 10.21 .17921

Ellenbroek, S. I., and van Rheenen, J. (2014). Imaging hallmarks of cancer in living mice. Nat. Rev. Cancer 14, 406-418. doi: 10.1038/nrc3742

Evensen, L., Johansen, P. L., Koster, G., Zhu, K., Herfindal, L., Speth, M., et al. (2016). Zebrafish as a model system for characterization of nanoparticles against cancer. Nanoscale 8, 862-877. doi: 10.1039/C5NR07289A 
Fazio, M., Ablain, J., Chuan, Y., Langenau, D. M., and Zon, L. I. (2020). Zebrafish patient avatars in cancer biology and precision cancer therapy. Nat. Rev. Cancer 20, 263-273. doi: 10.1038/s41568-020-0252-3

Fenizia, C., Bottino, C., Corbetta, S., Fittipaldi, R., Floris, P., Gaudenzi, G., et al. (2019). SMYD3 promotes the epithelial-mesenchymal transition in breast cancer. Nucleic Acids Res. 47, 1278-1293. doi: 10.1093/nar/gky1221

Fior, R., Povoa, V., Mendes, R. V., Carvalho, T., Gomes, A., Figueiredo, N., et al. (2017). Single-cell functional and chemosensitive profiling of combinatorial colorectal therapy in zebrafish xenografts. Proc. Natl. Acad. Sci. U.S.A. 114, E8234-e8243. doi: 10.1073/pnas.1618389114

Fisher, C. (2011). Immunohistochemistry in diagnosis of soft tissue tumours. Histopathology 58, 1001-1012. doi: 10.1111/j.1365-2559.2010.03707.x

Folkman, J. (1971). Tumor angiogenesis: therapeutic implications. N. Engl. J. Med. 285, 1182-1186. doi: 10.1056/NEJM197111182852108

Folkman, J. (1989). Successful treatment of an angiogenic disease. N. Engl. J. Med. 320, 1211-1212. doi: 10.1056/NEJM198905043201811

Follain, G., Osmani, N., Azevedo, A. S., Allio, G., Mercier, L., Karreman, M. A., et al. (2018). Hemodynamic forces tune the arrest, adhesion, and extravasation of circulating tumor cells. Dev. Cell. 45, 33-52.e12. doi: 10.1016/j.devcel.2018.02.015

Fornabaio, G., Barnhill, R. L., Lugassy, C., Bentolila, L. A., Cassoux, N., RomanRoman, S., et al. (2018). Angiotropism and extravascular migratory metastasis in cutaneous and uveal melanoma progression in a zebrafish model. Sci. Rep. 8:10448. doi: 10.1038/s41598-018-28515-6

Franich, A. A., Zivkovic, M. D., Ilic-Tomic, T., Dordevic, I. S., Nikodinovic-Runic, J., Pavic, A., et al. (2020). New minor groove covering DNA binding mode of dinuclear $\mathrm{Pt}(\mathrm{II})$ complexes with various pyridine-linked bridging ligands and dual anticancer-antiangiogenic activities. J. Biol. Inorg. Chem. 25, 395-409. doi: $10.1007 /$ s00775-020-01770-7

Frapolli, R., Marangon, E., Zaffaroni, M., Colombo, T., Falcioni, C., Bagnati, R., et al. (2006). Pharmacokinetics and metabolism in mice of IDN 5390 (13-(N-Boc-3-i-butylisoserinoyl)-C-7,8-seco-10-deacetylbaccatin III), a new oral c-seco-taxane derivative with antiangiogenic property effective on paclitaxel-resistant tumors. Drug Metab. Dispos. 34, 2028-2035. doi: $10.1124 / \mathrm{dmd} .106 .012153$

Gamble, J. T., Reed-Harris, Y., Barton, C. L., La Du, J., Tanguay, R., and Greenwood, J. A. (2018). Quantification of glioblastoma progression in zebrafish xenografts: adhesion to laminin alpha 5 promotes glioblastoma microtumor formation and inhibits cell invasion. Biochem. Biophys. Res. Commun. 506, 833-839. doi: 10.1016/j.bbrc.2018.10.076

Garcia-Caballero, M., Quesada, A. R., Medina, M. A., and Mari-Beffa, M. (2018). Fishing anti(lymph)angiogenic drugs with zebrafish. Drug Discov. Today 23, 366-374. doi: 10.1016/j.drudis.2017.10.018

Gaudenzi, G., Albertelli, M., Dicitore, A., Wurth, R., Gatto, F., Barbieri, F., et al. (2017). Patient-derived xenograft in zebrafish embryos: a new platform for translational research in neuroendocrine tumors. Endocrine 57, 214-219. doi: 10.1007/s12020-016-1048-9

Ghotra, V. P., He, S., de Bont, H., van der Ent, W., Spaink, H. P., van de Water, B., et al. (2012). Automated whole animal bio-imaging assay for human cancer dissemination. PLoS ONE 7:e31281. doi: 10.1371/journal.pone.0031281

Giallongo, C., Tibullo, D., Camiolo, G., Parrinello, N. L., Romano, A., Puglisi, F., et al. (2019). TLR4 signaling drives mesenchymal stromal cells commitment to promote tumor microenvironment transformation in multiple myeloma. Cell Death Dis. 10:704. doi: 10.1038/s41419-019-1959-5

Giallongo, C., Tibullo, D., Parrinello, N. L., La Cava, P., Di Rosa, M., Bramanti, V., et al. (2016). Granulocyte-like myeloid derived suppressor cells (G-MDSC) are increased in multiple myeloma and are driven by dysfunctional mesenchymal stem cells (MSC). Oncotarget 7, 85764-85775. doi: 10.18632/oncotarget.7969

Gill, J. A., Lowe, L., Nguyen, J., Liu, P. P., Blake, T., Venkatesh, B., et al. (2010). Enforced expression of Simian virus 40 large T-antigen leads to testicular germ cell tumors in zebrafish. Zebrafish 7, 333-341. doi: 10.1089/zeb.2010.0663

Gnosa, S., Capodanno, A., Murthy, R. V., Jensen, L. D., and Sun, X. F. (2016). AEG1 knockdown in colon cancer cell lines inhibits radiation-enhanced migration and invasion in vitro and in a novel in vivo zebrafish model. Oncotarget 7 , 81634-81644. doi: 10.18632/oncotarget.13155

Goddard, E. T., Fischer, J., and Schedin, P. (2016). A portal vein injection model to study liver metastasis of breast cancer. J. Vis. Exp. e54903. doi: 10.3791/54903
Goessling, W., North, T. E., and Zon, L. I. (2007). Ultrasound biomicroscopy permits in vivo characterization of zebrafish liver tumors. Nat. Methods 4, 551-553. doi: 10.1038/nmeth 1059

Gómez-Abenza, E., Ibáñez-Molero, S., García-Moreno, D., Fuentes, I., Zon, L. I., Mione, M. C., et al. (2019). Zebrafish modeling reveals that SPINT1 regulates the aggressiveness of skin cutaneous melanoma and its crosstalk with tumor immune microenvironment. J. Exp. Clin. Cancer Res. 38:405. doi: 10.1186/s13046-019-1389-3

Gong, C., Deng, S., Wu, Q., Xiang, M., Wei, X., Li, L., et al. (2013). Improving antiangiogenesis and anti-tumor activity of curcumin by biodegradable polymeric micelles. Biomaterials 34, 1413-1432. doi: 10.1016/j.biomaterials.2012.10.068

Granato, M., and Nusslein-Volhard, C. (1996). Fishing for genes controlling development. Curr. Opin. Genet. Dev. 6, 461-468. doi: 10.1016/S0959-437X(96)80068-2

Guo, S. (2009). Using zebrafish to assess the impact of drugs on neural development and function. Expert Opin. Drug Discov. 4, 715-726. doi: $10.1517 / 17460440902988464$

Gutierrez, A., Snyder, E. L., Marino-Enriquez, A., Zhang, Y. X., Sioletic, S., Kozakewich, E., et al. (2011). Aberrant AKT activation drives welldifferentiated liposarcoma. Proc. Natl. Acad. Sci. U.S.A. 108, 16386-16391. doi: 10.1073/pnas. 1106127108

Gutiérrez-Lovera, C., Martínez-Val, J., Cabezas-Sainz, P., López, R., Rubiolo, J. A., and Sánchez, L. (2019). In vivo toxicity assays in zebrafish embryos: a prerequisite for xenograft preclinical studies. Toxicol. Mech. Methods 29, 478-487. doi: 10.1080/15376516.2019.1611980

Haldi, M., Ton, C., Seng, W. L., and McGrath, P. (2006). Human melanoma cells transplanted into zebrafish proliferate, migrate, produce melanin, form masses and stimulate angiogenesis in zebrafish. Angiogenesis 9, 139-151. doi: 10.1007/s10456-006-9040-2

Hamilton, L., Astell, K. R., Velikova, G., and Sieger, D. (2016). A zebrafish live imaging model reveals differential responses of microglia toward glioblastoma cells in vivo. Zebrafish 13, 523-534. doi: 10.1089/zeb.2016.1339

Hamilton, L., Sieger, D., Ruiz, B. R., and Unciti-broceta, A. (2018). A novel zebrafish xenograft model for immunotherapeutic drug screening. Neurooncology 20:114s. doi: 10.1093/neuonc/nox238.063

Hason, M., and Bartuněk, P. (2019). Zebrafish models of cancer-new insights on modeling human cancer in a non-mammalian vertebrate. Genes 10:935. doi: 10.3390/genes10110935

He, S., Lamers, G. E., Beenakker, J. W., Cui, C., Ghotra, V. P., Danen, E. H., et al. (2012). Neutrophil-mediated experimental metastasis is enhanced by VEGFR inhibition in a zebrafish xenograft model. J. Pathol. 227, 431-445. doi: $10.1002 /$ path.4013

Heilmann, S., Ratnakumar, K., Langdon, E., Kansler, E., Kim, I., Campbell, N. R., et al. (2015). a quantitative system for studying metastasis using transparent zebrafish. Cancer Res. 75, 4272-4282. doi: 10.1158/0008-5472.CAN-14-3319

Herbrink, M., Nuijen, B., Schellens, J. H., and Beijnen, J. H. (2015). Variability in bioavailability of small molecular tyrosine kinase inhibitors. Cancer Treat. Rev. 41, 412-422. doi: 10.1016/j.ctrv.2015.03.005

Hidalgo, M., Amant, F., Biankin, A. V., Budinska, E., Byrne, A. T., Caldas, C., et al. (2014). Patient-derived xenograft models: an emerging platform for translational cancer research. Cancer Discov. 4, 998-1013. doi: 10.1158/2159-8290.CD-14-0001

Hill, D., Chen, L., Snaar-Jagalska, E., and Chaudhry, B. (2018). Embryonic zebrafish xenograft assay of human cancer metastasis. F1000Research 7:1682. doi: 10.12688/f1000research.16659.2

Hirschmann-Jax, C., Foster, A. E., Wulf, G. G., Nuchtern, J. G., Jax, T. W., Gobel, U., et al. (2004). A distinct "side population" of cells with high drug efflux capacity in human tumor cells. Proc. Natl. Acad. Sci. U.S.A. 101, 14228-14233. doi: 10.1073/pnas.0400067101

Howe, K., Clark, M. D., Torroja, C. F., Torrance, J., Berthelot, C., Muffato, M., et al. (2013). The zebrafish reference genome sequence and its relationship to the human genome. Nature 496, 498-503. doi: 10.1038/nature12111

Hyenne, V., Ghoroghi, S., Collot, M., Bons, J., Follain, G., Harlepp, S., et al. (2019). Studying the fate of tumor extracellular vesicles at high spatiotemporal resolution using the zebrafish embryo. Dev. Cell. 48, 554-572.e557. doi: 10.1016/j.devcel.2019.01.014 
Ignatius, M. S., Chen, E., Elpek, N. M., Fuller, A. Z., Tenente, I. M., Clagg, R., et al. (2012). In vivo imaging of tumor-propagating cells, regional tumor heterogeneity, and dynamic cell movements in embryonal rhabdomyosarcoma. Cancer Cell. 21, 680-693. doi: 10.1016/j.ccr.2012.03.043

Ignatius, M. S., Hayes, M. N., Lobbardi, R., Chen, E. Y., McCarthy, K. M., Sreenivas, P., et al. (2017). The NOTCH1/SNAIL1/MEF2C pathway regulates growth and self-renewal in embryonal rhabdomyosarcoma. Cell Rep. 19, 2304-2318. doi: 10.1016/j.celrep.2017.05.061

Irion, U., Krauss, J., and Nüsslein-Volhard, C. (2014). Precise and efficient genome editing in zebrafish using the CRISPR/Cas9 system. Development 141, 4827-4830. doi: 10.1242/dev.115584

Jao, L. E., Wente, S. R., and Chen, W. (2013). Efficient multiplex biallelic zebrafish genome editing using a CRISPR nuclease system. Proc. Natl. Acad. Sci. U.S.A. 110, 13904-13909. doi: 10.1073/pnas.1308335110

Jászai, J., and Schmidt, M. H. H. (2019). Trends and challenges in tumor antiangiogenic therapies. Cells 8:1102. doi: 10.3390/cells8091102

Jeong, J. Y., Kwon, H. B., Ahn, J. C., Kang, D., Kwon, S. H., Park, J. A., et al. (2008). Functional and developmental analysis of the blood-brain barrier in zebrafish. Brain Res. Bull. 75, 619-628. doi: 10.1016/j.brainresbull.2007.10.043

Jo, D. H., Son, D., Na, Y., Jang, M., Choi, J. H., Kim, J. H., et al. (2013). Orthotopic transplantation of retinoblastoma cells into vitreous cavity of zebrafish for screening of anticancer drugs. Mol. Cancer 12:71. doi: 10.1186/1476-4598-12-71

Johansson, P. A., Brooks, K., Newell, F., Palmer, J. M., Wilmott, J. S., Pritchard, A. L., et al. (2020). Whole genome landscapes of uveal melanoma show an ultraviolet radiation signature in iris tumours. Nat. Commun. 11:2408. doi: 10.1038/s41467-020-16276-8

Jung, I. H., Chung, Y. Y., Jung, D. E., Kim, Y. J., Kim, D. H., Kim, K. S., et al. (2016). Impaired lymphocytes development and xenotransplantation of gastrointestinal tumor cells in Prkdc-Null SCID zebrafish model. Neoplasia 18, 468-479. doi: 10.1016/j.neo.2016.06.007

Jung, I. H., Jung, D. E., Park, Y. N., Song, S. Y., and Park, S. W. (2011). Aberrant Hedgehog ligands induce progressive pancreatic fibrosis by paracrine activation of myofibroblasts and ductular cells in transgenic zebrafish. PLoS ONE 6:e27941. doi: 10.1371/journal.pone.0027941

Junttila, M. R., and de Sauvage, F. J. (2013). Influence of tumour microenvironment heterogeneity on therapeutic response. Nature 501, 346-354. doi: 10.1038/nature12626

Keller, E. T., and Murtha, J. M. (2004). The use of mature zebrafish (Danio rerio) as a model for human aging and disease. Comp. Biochem. Physiol. C. Toxicol. Pharmacol. 138, 335-341. doi: 10.1016/j.cca.2004.04.001

Kim, I. S., Heilmann, S., Kansler, E. R., Zhang, Y., Zimmer, M., Ratnakumar, K., et al. (2017). Microenvironment-derived factors driving metastatic plasticity in melanoma. Nat. Commun. 8:14343. doi: 10.1038/ncomms14343

Konantz, M., Balci, T. B., Hartwig, U. F., Dellaire, G., Andre, M. C., Berman, J. N., et al. (2012). Zebrafish xenografts as a tool for in vivo studies on human cancer. Ann. N. Y. Acad. Sci. 1266, 124-137. doi: 10.1111/j.1749-6632.2012.06575.x

Konantz, M., Müller, J. S., and Lengerke, C. (2019). Zebrafish xenografts for the in vivo analysis of healthy and malignant human hematopoietic cells. Methods Mol. Biol. 2017, 205-217. doi: 10.1007/978-1-4939-9574-5_16

Krueger, M., and Bechmann, I. (2010). CNS pericytes: concepts, misconceptions, and a way out. Glia 58, 1-10. doi: 10.1002/glia.20898

Kulkarni, P., Chaudhari, G. H., Sripuram, V., Banote, R. K., Kirla, K. T., Sultana, R., et al. (2014). Oral dosing in adult zebrafish: proof-of-concept using pharmacokinetics and pharmacological evaluation of carbamazepine. Pharmacol. Rep. 66, 179-183. doi: 10.1016/j.pharep.2013.06.012

Labernadie, A., and Trepat, X. (2018). Sticking, steering, squeezing and shearing: cell movements driven by heterotypic mechanical forces. Curr. Opin. Cell Biol. 54, 57-65. doi: 10.1016/j.ceb.2018.04.008

Lal, S., La Du, J., Tanguay, R. L., and Greenwood, J. A. (2012). Calpain 2 is required for the invasion of glioblastoma cells in the zebrafish brain microenvironment. J. Neurosci. Res. 90, 769-781. doi: 10.1002/jnr.22794

Lam, S. H., Chua, H. L., Gong, Z., Lam, T. J., and Sin, Y. M. (2004). Development and maturation of the immune system in zebrafish, Danio rerio: a gene expression profiling, in situ hybridization and immunological study. Dev. Comp. Immunol. 28, 9-28. doi: 10.1016/S0145-305X(03)00103-4
Lam, S. H., Chua, H. L., Gong, Z., Wen, Z., Lam, T. J., and Sin, Y. M. (2002). Morphologic transformation of the thymus in developing zebrafish. Dev. Dyn. 225, 87-94. doi: 10.1002/dvdy.10127

Langenau, D. M., Ferrando, A. A., Traver, D., Kutok, J. L., Hezel, J. P., Kanki, J. P., et al. (2004). In vivo tracking of T cell development, ablation, and engraftment in transgenic zebrafish. Proc. Natl. Acad. Sci. U.S.A. 101, 7369-7374. doi: 10.1073/pnas.0402248101

Langenau, D. M., Keefe, M. D., Storer, N. Y., Guyon, J. R., Kutok, J. L., Le, X., et al. (2007). Effects of RAS on the genesis of embryonal rhabdomyosarcoma. Genes Dev. 21, 1382-1395. doi: 10.1101/gad.1545007

Langenau, D. M., Traver, D., Ferrando, A. A., Kutok, J. L., Aster, J. C., Kanki, J. P., et al. (2003). Myc-induced T cell leukemia in transgenic zebrafish. Science 299, 887-890. doi: 10.1126/science. 1080280

Langenau, D. M., and Zon, L. I. (2005). The zebrafish: a new model of T-cell and thymic development. Nat. Rev. Immunol. 5, 307-317. doi: 10.1038/nri1590

Latifi, A., Abubaker, K., Castrechini, N., Ward, A. C., Liongue, C., Dobill, F., et al. (2011). Cisplatin treatment of primary and metastatic epithelial ovarian carcinomas generates residual cells with mesenchymal stem cell-like profile. $J$. Cell. Biochem. 112, 2850-2864. doi: 10.1002/jcb.23199

Lee, S. L., Rouhi, P., Dahl Jensen, L., Zhang, D., Ji, H., Hauptmann, G., et al. (2009). Hypoxia-induced pathological angiogenesis mediates tumor cell dissemination, invasion, and metastasis in a zebrafish tumor model. Proc. Natl. Acad. Sci. U.S.A. 106, 19485-19490. doi: 10.1073/pnas.0909228106

Letrado, P., de Miguel, I., Lamberto, I., Díez-Martínez, R., and Oyarzabal, J. (2018). Zebrafish: speeding up the cancer drug discovery process. Cancer Res. 78, 6048-6058. doi: 10.1158/0008-5472.CAN-18-1029

Leung, L. C., Wang, G. X., and Mourrain, P. (2013). Imaging zebrafish neural circuitry from whole brain to synapse. Front. Neural Circuits. 7:76. doi: 10.3389/fncir.2013.00076

Levin, V. A., Dolginow, D., Landahl, H. D., Yorke, C., and Csejtey, J. (1984). Relationship of octanol/water partition coefficient and molecular weight to cellular permeability and partitioning in s49 lymphoma cells. Pharm. Res. 1, 259-266. doi: 10.1023/A:1016393902123

Levin, V. A., Tonge, P. J., Gallo, J. M., Birtwistle, M. R., Dar, A. C., Iavarone, A., et al. (2015). cns anticancer drug discovery and development conference white paper. Neuro-oncology 17(Suppl 6):vil-26. doi: 10.1093/neuonc/nov169

Li, P., Lahvic, J. L., Binder, V., Pugach, E. K., Riley, E. B., Tamplin, O. J., et al. (2015). Epoxyeicosatrienoic acids enhance embryonic haematopoiesis and adult marrow engraftment. Nature 523, 468-471. doi: 10.1038/nature14569

Li, Y., Song, X., Yi, X., Wang, R., Lee, S. M., Wang, X., et al. (2017). Zebrafish: A visual model to evaluate the biofate of transferrin receptor-targeted 7Peptidedecorated coumarin 6 micelles. ACS Appl. Mater. Interfaces 9, 39048-39058. doi: 10.1021/acsami.7b12809

Li, Z., Huang, X., Zhan, H., Zeng, Z., Li, C., Spitsbergen, J. M., et al. (2012). Inducible and repressable oncogene-addicted hepatocellular carcinoma in Tet-on xmrk transgenic zebrafish. J. Hepatol. 56, 419-425. doi: 10.1016/j.jhep.2011.07.025

Lieschke, G. J., and Currie, P. D. (2007). Animal models of human disease: zebrafish swim into view. Nat. Rev. Genet 8, 353-367. doi: 10.1038/nrg2091

Lin, H. S., Huang, Y. L., Wang, Y. S., Hsiao, E., Hsu, T. A., Shiao, H. Y., et al. (2019). Identification of novel anti-liver cancer small molecules with better therapeutic index than sorafenib via zebrafish drug screening platform. Cancers 11:739. doi: 10.3390/cancers11060739

Lin, J., Zhang, W., Zhao, J. J., Kwart, A. H., Yang, C., Ma, D., et al. (2016). A clinically relevant in vivo zebrafish model of human multiple myeloma to study preclinical therapeutic efficacy. Blood 128, 249-252. doi: 10.1182/blood-2016-03-704460

Liu, C., Zhang, Y., Lim, S., Hosaka, K., Yang, Y., Pavlova, T., et al. (2017). A zebrafish model discovers a novel mechanism of stromal fibroblast-mediated cancer metastasis. Clin. Cancer Res. 23, 4769-4779. doi: 10.1158/1078-0432.CCR-17-0101

Liu, J., Huang, Z., Yang, L., Wang, X., Wang, S., Li, C., et al. (2019). Embryonic stem cells modulate the cancer-permissive microenvironment of human uveal melanoma. Theranostics 9, 4764-4778. doi: 10.7150/thno.33139

Liu, S., and Leach, S. D. (2011). Zebrafish models for cancer. Annu. Rev. Pathol. 6, 71-93. doi: 10.1146/annurev-pathol-011110-130330 
Lizardo, M. M., and Sorensen, P. H. (2018). Practical considerations in studying metastatic lung colonization in osteosarcoma using the pulmonary metastasis assay. J. Vis. Exp. e56332. doi: 10.3791/56332

Mandelbaum, J., Shestopalov, I. A., Henderson, R. E., Chau, N. G., Knoechel, B., Wick, M. J., et al. (2018). Zebrafish blastomere screen identifies retinoic acid suppression of MYB in adenoid cystic carcinoma. J. Exp. Med. 215, 2673-2685. doi: 10.1084/jem.20180939

Marques, I. J., Weiss, F. U., Vlecken, D. H., Nitsche, C., Bakkers, J., Lagendijk, A. K., et al. (2009). Metastatic behaviour of primary human tumours in a zebrafish xenotransplantation model. BMC Cancer 9:128. doi: 10.1186/1471-2407-9-128

Mizgireuv, I. V., and Revskoy, S. Y. (2006). Transplantable tumor lines generated in clonal zebrafish. Cancer Res. 66, 3120-3125. doi: 10.1158/0008-5472.CAN-05-3800

Moore, J. C., Tang, Q., Yordan, N. T., Moore, F. E., Garcia, E. G., Lobbardi, R., et al. (2016). Single-cell imaging of normal and malignant cell engraftment into optically clear prkdc-null SCID zebrafish. J. Exp. Med. 213, 2575-2589. doi: $10.1084 /$ jem. 20160378

Morton, C. L., and Houghton, P. J. (2007). Establishment of human tumor xenografts in immunodeficient mice. Nat. Protoc. 2, 247-250. doi: $10.1038 /$ nprot.2007.25

Neumann, J. C., Lillard, K., Damoulis, V., and Amatruda, J. F. (2011). Zebrafish models of germ cell tumor. Methods Cell Biol. 105, 3-24. doi: 10.1016/B978-0-12-381320-6.00001-1

Neuwelt, E. A. (2004). Mechanisms of disease: the bloodbrain barrier. Neurosurgery 54, 131-140; discussion 141-132. doi: 10.1227/01.NEU.0000097715.11966.8E

Nguyen, A. T., Emelyanov, A., Koh, C. H., Spitsbergen, J. M., Parinov, S., and Gong, Z. (2012). An inducible kras(V12) transgenic zebrafish model for liver tumorigenesis and chemical drug screening. Dis. Model. Mech. 5, 63-72. doi: $10.1242 / \mathrm{dmm} .008367$

Nicoli, S., Ribatti, D., Cotelli, F., and Presta, M. (2007). Mammalian tumor xenografts induce neovascularization in zebrafish embryos. Cancer Res. 67, 2927-2931. doi: 10.1158/0008-5472.CAN-06-4268

Ober, E. A., Field, H. A., and Stainier, D. Y. (2003). From endoderm formation to liver and pancreas development in zebrafish. Mech. Dev. 120, 5-18. doi: 10.1016/S0925-4773(02)00327-1

O'Brown, N. M., Megason, S. G., and Gu, C. (2019). Suppression of transcytosis regulates zebrafish blood-brain barrier function. Elife 8:e47326. doi: 10.7554/eLife.47326

Parada-Kusz, M., Penaranda, C., Hagedorn, E. J., Clatworthy, A., Nair, A. V., Henninger, J. E., et al. (2018). Generation of mouse-zebrafish hematopoietic tissue chimeric embryos for hematopoiesis and host-pathogen interaction studies. Dis. Models Mechan. 11:dmm034876. doi: 10.1242/dmm.034876

Park, S. W., Davison, J. M., Rhee, J., Hruban, R. H., Maitra, A., and Leach, S. D. (2008). Oncogenic KRAS induces progenitor cell expansion and malignant transformation in zebrafish exocrine pancreas. Gastroenterology 134 , 2080-2090. doi: 10.1053/j.gastro.2008.02.084

Patton, E. E., Widlund, H. R., Kutok, J. L., Kopani, K. R., Amatruda, J. F., Murphey, R. D., et al. (2005). BRAF mutations are sufficient to promote nevi formation and cooperate with p53 in the genesis of melanoma. Curr. Biol. 15, 249-254. doi: 10.1016/j.cub.2005.01.031

Paulussen, M., Ahrens, S., Burdach, S., Craft, A., Dockhorn-Dworniczak, B., Dunst, J., et al. (1998). Primary metastatic (stage IV) ewing tumor: survival analysis of 171 patients from the EICESS studies. European intergroup cooperative ewing sarcoma studies. Ann. Oncol. 9:275-281. doi: 10.1023/A:1008208511815

Pontes, K. C. S., Groenewoud, A., Cao, J., Ataide, L. M. S., Snaar-Jagalska, E., and Jager, M. J. (2017). Evaluation of (fli:gfp) casper zebrafish embryos as a model for human conjunctival melanoma. Invest. Ophthalmol. Vis. Sci. 58, 6065-6071. doi: 10.1167/iovs.17-22023

Pringle, E. S., Wertman, J., Melong, N., Coombs, A. J., Young, A. L., O'Leary, D., et al. (2019). The zebrafish xenograft platform-a novel tool for modeling KSHV-associated diseases. Viruses 12:12. doi: 10.3390/v12010012

Pruvot, B., Jacquel, A., Droin, N., Auberger, P., Bouscary, D., Tamburini, J., et al. (2011). Leukemic cell xenograft in zebrafish embryo for investigating drug efficacy. Haematologica 96, 612-616. doi: 10.3324/haematol.2010.031401

Qin, X., Yan, M., Zhang, J., Xu, Q., Lv, Z., and Chen, W. (2016). Establishment of a highly metastatic buccal squamous cell carcinoma cell line from a SpragueDawley Rat. Arch. Oral Biol. 62, 1-9. doi: 10.1016/j.archoralbio.2015.11.003
Raeber, G. P., Lutolf, M. P., and Hubbell, J. A. (2005). Molecularly engineered PEG hydrogels: a novel model system for proteolytically mediated cell migration. Biophys. J. 89, 1374-1388. doi: 10.1529/biophysj.104.050682

Rampazzo, E., Persano, L., Pistollato, F., Moro, E., Frasson, C., Porazzi, P., et al. (2013). Wnt activation promotes neuronal differentiation of glioblastoma. Cell Death Dis. 4:e500. doi: 10.1038/cddis.2013.32

Rebelo de Almeida, C., Mendes, R. V., Pezzarossa, A., Gago, J., Carvalho, C., Alves, A., et al. (2020). Zebrafish xenografts as a fast screening platform for bevacizumab cancer therapy. Commun. Biol. 3:299. doi: 10.1038/s42003-020-1015-0

Roh-Johnson, M., Shah, A., Stonick, J., Poudel, K., Kargl, J., Yang, G., et al. (2017). Macrophage-dependent cytoplasmic transfer during melanoma invasion in vivo. Dev. Cell. 43, 549-562.e546. doi: 10.1016/j.devcel.2017.11.003

Rosfjord, E., Lucas, J., Li, G., and Gerber, H. P. (2014). Advances in patient-derived tumor xenografts: from target identification to predicting clinical response rates in oncology. Biochem. Pharmacol. 91, 135-143. doi: 10.1016/j.bcp.2014.06.008

Rudner, L. A., Brown, K. H., Dobrinski, K. P., Bradley, D. F., Garcia, M. I., Smith, A. C., et al. (2011). Shared acquired genomic changes in zebrafish and human T-ALL. Oncogene 30, 4289-4296. doi: 10.1038/onc.2011.138

Sabaawy, H. E., Azuma, M., Embree, L. J., Tsai, H. J., Starost, M. F., and Hickstein, D. D. (2006). TEL-AML1 transgenic zebrafish model of precursor B cell acute lymphoblastic leukemia. Proc. Natl. Acad. Sci. U.S.A. 103, 15166-15171. doi: $10.1073 /$ pnas. 0603349103

Sant, K. E., and Timme-Laragy, A. R. (2018). Zebrafish as a model for toxicological perturbation of yolk and nutrition in the early embryo. Curr. Environ. Health Rep. 5, 125-133. doi: 10.1007/s40572-018-0183-2

Shi, L., Sheng, J., Wang, M., Luo, H., Zhu, J., Zhang, B., et al. (2019). Combination therapy of TGF-beta blockade and commensal-derived probiotics provides enhanced antitumor immune response and tumor suppression. Theranostics 9 , 4115-4129. doi: 10.7150/thno.35131

Sieber, S., Grossen, P., Detampel, P., Siegfried, S., Witzigmann, D., and Huwyler, J. (2017). Zebrafish as an early stage screening tool to study the systemic circulation of nanoparticulate drug delivery systems in vivo. J. Control. Release 264, 180-191. doi: 10.1016/j.jconrel.2017.08.023

Simbulan-Rosenthal, C. M., Dougherty, R., Vakili, S., Ferraro, A. M., Kuo, L. W., Alobaidi, R., et al. (2019). CRISPR-Cas9 knockdown and induced expression of CD133 reveal essential roles in melanoma invasion and metastasis. Cancers 11:1490. doi: 10.3390/cancers 11101490

Siolas, D., and Hannon, G. J. (2013). Patient-derived tumor xenografts: transforming clinical samples into mouse models. Cancer Res. 73, 5315-5319. doi: 10.1158/0008-5472.CAN-13-1069

Smith, A. C., Raimondi, A. R., Salthouse, C. D., Ignatius, M. S., Blackburn, J. S., Mizgirev, I. V., et al. (2010). High-throughput cell transplantation establishes that tumor-initiating cells are abundant in zebrafish T-cell acute lymphoblastic leukemia. Blood 115, 3296-3303. doi: 10.1182/blood-2009-10-246488

Smith, M. P., Ferguson, J., Arozarena, I., Hayward, R., Marais, R., Chapman, A., et al. (2013). Effect of SMURF2 targeting on susceptibility to MEK inhibitors in melanoma. J. Natl. Cancer Inst. 105, 33-46. doi: 10.1093/jnci/djs471

Spaink, H. P., Cui, C., Wiweger, M. I., Jansen, H. J., Veneman, W. J., Marín-Juez, R., et al. (2013). Robotic injection of zebrafish embryos for high-throughput screening in disease models. Methods 62, 246-254. doi: 10.1016/j.ymeth.2013.06.002

Stoletov, K., Kato, H., Zardouzian, E., Kelber, J., Yang, J., Shattil, S., et al. (2010). Visualizing extravasation dynamics of metastatic tumor cells. J. Cell Sci. 123, 2332-2341. doi: 10.1242/jcs.069443

Stoletov, K., Montel, V., Lester, R. D., Gonias, S. L., and Klemke, R. (2007). High-resolution imaging of the dynamic tumor cell vascular interface in transparent zebrafish. Proc. Natl. Acad. Sci. U.S.A. 104, 17406-17411. doi: $10.1073 /$ pnas.0703446104

Stroka, K. M., and Konstantopoulos, K. (2014). Physical biology in cancer. 4. physical cues guide tumor cell adhesion and migration. Am. J. Physiol. Cell Physiol. 306, C98-c109. doi: 10.1152/ajpcell.00289.2013

Stuelten, C. H., Parent, C. A., and Montell, D. J. (2018). Cell motility in cancer invasion and metastasis: insights from simple model organisms. Nat. Rev. Cancer 18, 296-312. doi: 10.1038/nrc.2018.15

Stuurman, F. E., Nuijen, B., Beijnen, J. H., and Schellens, J. H. (2013). Oral anticancer drugs: mechanisms of low bioavailability and strategies for improvement. Clin. Pharm. 52, 399-414. doi: 10.1007/s40262-013-0040-2 
Sun, D. Y., Wu, J. Q., He, Z. H., He, M. F., and Sun, H. B. (2019). Cancer-associated fibroblast regulate proliferation and migration of prostate cancer cells through TGF-beta signaling pathway. Life Sci. 235:116791. doi: 10.1016/j.lfs.2019.116791

Sung, Y. H., Kim, J. M., Kim, H. T., Lee, J., Jeon, J., Jin, Y., et al. (2014). Highly efficient gene knockout in mice and zebrafish with RNA-guided endonucleases. Genome Res. 24, 125-131. doi: 10.1101/gr.163394.113

Tang, Q., Abdelfattah, N. S., Blackburn, J. S., Moore, J. C., Martinez, S. A., Moore, F. E., et al. (2014). Optimized cell transplantation using adult rag2 mutant zebrafish. Nat. Methods 11, 821-824. doi: 10.1038/nmeth.3031

Tang, Q., Moore, J. C., Ignatius, M. S., Tenente, I. M., Hayes, M. N., Garcia, E. G., et al. (2016). Imaging tumour cell heterogeneity following cell transplantation into optically clear immune-deficient zebrafish. Nat. Commun. 7:10358. doi: $10.1038 /$ ncomms10358

Tanner, K. (2018). Perspective: The role of mechanobiology in the etiology of brain metastasis. APL Bioeng. 2:031801. doi: 10.1063/1.5024394

Tchoghandjian, A., Baeza-Kallee, N., Beclin, C., Metellus, P., Colin, C., Ducray, F., et al. (2012). Cortical and subventricular zone glioblastoma-derived stem-like cells display different molecular profiles and differential in vitro and in vivo properties. Ann. Surg. Oncol. 19, S608-619. doi: 10.1245/s10434-011-2093-5

Tentler, J. J., Tan, A. C., Weekes, C. D., Jimeno, A., Leong, S., Pitts, T. M., et al. (2012). Patient-derived tumour xenografts as models for oncology drug development. Nat. Rev. Clin. Oncol. 9, 338-350. doi: 10.1038/nrclinonc.2012.61

Tomasin, R., Martin, A., and Cominetti, M. R. (2019). Metastasis and cachexia: alongside in clinics, but not so in animal models. J. Cachexia Sarcopenia Muscle. 10, 1183-1194. doi: 10.1002/jcsm. 12475

Tran, T. C., Sneed, B., Haider, J., Blavo, D., White, A., Aiyejorun, T., et al. (2007). Automated, quantitative screening assay for antiangiogenic compounds using transgenic zebrafish. Cancer Res. 67, 11386-11392. doi: 10.1158/0008-5472.CAN-07-3126

Traver, D., Paw, B. H., Poss, K. D., Penberthy, W. T., Lin, S., and Zon, L. I. (2003). Transplantation and in vivo imaging of multilineage engraftment in zebrafish bloodless mutants. Nat. Immunol. 4, 1238-1246. doi: 10.1038/ni1007

Tsarouchas, T. M., Wehner, D., Cavone, L., Munir, T., Keatinge, M., Lambertus, M., et al. (2018). Dynamic control of proinflammatory cytokines Il-1 $\beta$ and Tnf$\alpha$ by macrophages in zebrafish spinal cord regeneration. Nat. Commun. 9:4670. doi: 10.1038/s41467-018-07036-w

Tulotta, C., Stefanescu, C., Beletkaia, E., Bussmann, J., Tarbashevich, K., Schmidt, T., et al. (2016). Inhibition of signaling between human CXCR4 and zebrafish ligands by the small molecule IT1t impairs the formation of triple-negative breast cancer early metastases in a zebrafish xenograft model. Dis. Model. Mech. 9, 141-153. doi: 10.1242/dmm.023275

Tulotta, C., Stefanescu, C., Chen, Q., Torraca, V., Meijer, A. H., and SnaarJagalska, B. E. (2019). CXCR4 signaling regulates metastatic onset by controlling neutrophil motility and response to malignant cells. Sci. Rep. 9:2399. doi: 10.1038/s41598-019-38643-2

van der Ent, W., Burrello, C., Teunisse, A. F., Ksander, B. R., van der Velden, P. A., Jager, M. J., et al. (2014a). Modeling of human uveal melanoma in zebrafish xenograft embryos. Invest. Ophthalmol. Vis. Sci. 55, 6612-6622. doi: 10.1167 /iovs.14-15202

van der Ent, W., Jochemsen, A. G., Teunisse, A. F., Krens, S. F., Szuhai, K., Spaink, H. P., et al. (2014b). Ewing sarcoma inhibition by disruption of EWSR1FLI1 transcriptional activity and reactivation of p53. J. Pathol. 233, 415-424. doi: $10.1002 /$ path.4378

Vaughan, L., Tan, C. T., Chapman, A., Nonaka, D., Mack, N. A., Smith, D., et al. (2015). HUWE1 ubiquitylates and degrades the RAC activator TIAM1 promoting cell-cell adhesion disassembly, migration, and invasion. Cell Rep. 10, 88-102. doi: 10.1016/j.celrep.2014.12.012

Vazquez Rodriguez, G., Abrahamsson, A., Jensen, L. D., and Dabrosin, C. (2017). Estradiol promotes breast cancer cell migration via recruitment and activation of neutrophils. Cancer Immunol. Res. 5, 234-247. doi: 10.1158/2326-6066.CIR-16-0150

Veinotte, C. J., Dellaire, G., and Berman, J. N. (2014). Hooking the big one: the potential of zebrafish xenotransplantation to reform cancer drug screening in the genomic era. Dis. Model. Mech. 7, 745-754. doi: 10.1242/dmm.015784

Vicente, C., Arriazu, E., Martínez-Balsalobre, E., Peris, I., Marcotegui, N., García-Ramírez, P., et al. (2020). A novel FTY720 analogue targets SET-PP2A interaction and inhibits growth of acute myeloid leukemia cells without inducing cardiac toxicity. Cancer Lett. 468, 1-13. doi: 10.1016/j.canlet.2019.10.007

Vinothkumar, R., Nicole, M., Wing Hing, W., Benjamin, K., Tong, R. S., Nithin, M., et al. (2019). Humanized zebrafish enhance human hematopoietic stem cell survival and promote acute myeloid leukemia clonal diversity. Haematologica 105, 2391-2399. doi: 10.3324/haematol.2019.223040

Vittori, M., Breznik, B., Gredar, T., Hrovat, K., Bizjak Mali, L., and Lah, T. T. (2016). Imaging of human glioblastoma cells and their interactions with mesenchymal stem cells in the zebrafish (Danio rerio) embryonic brain. Radiol. Oncol. 50, 159-167. doi: 10.1515/raon-2016-0017

Wang, C., Tao, W., Wang, Y., Bikow, J., Lu, B., Keating, A., et al. (2010). Rosuvastatin, identified from a zebrafish chemical genetic screen for antiangiogenic compounds, suppresses the growth of prostate cancer. Eur. Urol. 58, 418-426. doi: 10.1016/j.eururo.2010.05.024

Wang, J., Cao, Z., Zhang, X. M., Nakamura, M., Sun, M., Hartman, J., et al. (2015). Novel mechanism of macrophage-mediated metastasis revealed in a zebrafish model of tumor development. Cancer Res. 75, 306-315. doi: 10.1158/0008-5472.CAN-14-2819

Weiss, F. U., Marques, I. J., Woltering, J. M., Vlecken, D. H., Aghdassi, A., Partecke, L. I., et al. (2009). Retinoic acid receptor antagonists inhibit miR-10a expression and block metastatic behavior of pancreatic cancer. Gastroenterology 137, 2136-2145.e2131-2137. doi: 10.1053/j.gastro.2009.08.065

Welker, A. M., Jaros, B. D., Puduvalli, V. K., Imitola, J., Kaur, B., and Beattie, C. E. (2016). Standardized orthotopic xenografts in zebrafish reveal glioma cellline-specific characteristics and tumor cell heterogeneity. Dis. Model. Mech. 9, 199-210. doi: 10.1242/dmm.022921

Wenger, A., Larsson, S., Danielsson, A., Elbæk, K. J., Kettunen, P., Tisell, M., et al. (2017). Stem cell cultures derived from pediatric brain tumors accurately model the originating tumors. Oncotarget 8, 18626-18639. doi: 10.18632 /oncotarget.14826

Wertman, J., Veinotte, C. J., Dellaire, G., and Berman, J. N. (2016). The zebrafish xenograft platform: evolution of a novel cancer model and preclinical screening tool. Adv. Exp. Med. Biol. 916, 289-314. doi: 10.1007/978-3-319-30654-4_13

White, R., Rose, K., and Zon, L. (2013). Zebrafish cancer: the state of the art and the path forward. Nat. Rev. Cancer 13, 624-636. doi: 10.1038/nrc3589

White, R. M., Sessa, A., Burke, C., Bowman, T., LeBlanc, J., Ceol, C., et al. (2008) Transparent adult zebrafish as a tool for in vivo transplantation analysis. Cell Stem Cell. 2, 183-189. doi: 10.1016/j.stem.2007.11.002

Wong, C. W., Han, H. W., Tien, Y. W., and Hsu, S. H. (2019). Biomaterial substrate-derived compact cellular spheroids mimicking the behavior of pancreatic cancer and microenvironment. Biomaterials 213:119202. doi: 10.1016/j.biomaterials.2019.05.013

Wu, J. Q., Fan, R. Y., Zhang, S. R., Li, C. Y., Shen, L. Z., Wei, P., et al. (2020). A systematical comparison of anti-angiogenesis and anti-cancer efficacy of ramucirumab, apatinib, regorafenib and cabozantinib in zebrafish model. Life Sci. 247:117402. doi: 10.1016/j.lfs.2020.117402

Wu, J. Q., Zhai, J., Li, C. Y., Tan, A. M., Wei, P., Shen, L. Z., et al. (2017). Patient-derived xenograft in zebrafish embryos: a new platform for translational research in gastric cancer. J. Exp. Clin. Cancer Res. 36:160. doi: 10.1186/s13046-017-0631-0

Wullimann, M. F., and Mueller, T. (2004). Teleostean and mammalian forebrains contrasted: evidence from genes to behavior. J. Comp. Neurol. 475, 143-162. doi: 10.1002/cne.20183

Xie, Z., Guo, W., Guo, N., Huangfu, M., Liu, H., Lin, M., et al. (2018). Targeting tumor hypoxia with stimulus-responsive nanocarriers in overcoming drug resistance and monitoring anticancer efficacy. Acta Biomater. 71, 351-362. doi: 10.1016/j.actbio.2018.03.013

Yan, C., Brunson, D. C., Tang, Q., Do, D., Iftimia, N. A., Moore, J. C., et al. (2019). Visualizing engrafted human cancer and therapy responses in immunodeficient zebrafish. Cell 177, 1903-1914.e1914. doi: 10.1016/j.cell.2019.04.004

Yang, Q., Salim, L., Yan, C., and Gong, Z. (2019). Rapid analysis of effects of environmental toxicants on tumorigenesis and inflammation using a transgenic zebrafish model for liver cancer. Marine Biotechnol. 21, 396-405. doi: 10.1007/s10126-019-09889-8

Zeng, A., Ye, T., Cao, D., Huang, X., Yang, Y., Chen, X., et al. (2017). Identify a blood-brain barrier penetrating drug-tnb using zebrafish orthotopic glioblastoma xenograft model. Sci. Rep. 7:14372. doi: 10.1038/s41598-017-14766-2 
Zhang, F., Qin, W., Zhang, J. P., and Hu, C. Q. (2015). Antibiotic toxicity and absorption in zebrafish using liquid chromatography-tandem mass spectrometry. PLoS ONE 10:e0124805. doi: 10.1371/journal.pone.0124805

Zhang, M., Di Martino, J. S., Bowman, R. L., Campbell, N. R., Baksh, S. C., Simon-Vermot, T., et al. (2018). Adipocytederived lipids mediate melanoma progression via FATP proteins. Cancer Discov. 8, 1006-1025. doi: 10.1158/2159-8290.CD-17-1 371

Zhao, C., Wang, X., Zhao, Y., Li, Z., Lin, S., Wei, Y., et al. (2011a). A novel xenograft model in zebrafish for highresolution investigating dynamics of neovascularization in tumors. PLoS ONE 6:e21768. doi: 10.1371/journal.pone.00 21768

Zhao, C., Yang, H., Shi, H., Wang, X., Chen, X., Yuan, Y., et al. (2011b). Distinct contributions of angiogenesis and vascular co-option during the initiation of primary microtumors and micrometastases. Carcinogenesis. 32, 1143-1150. doi: $10.1093 /$ carcin/bgr076
Zhao, H., Tang, C., Cui, K., Ang, B. T., and Wong, S. T. (2009). A screening platform for glioma growth and invasion using bioluminescence imaging. laboratory investigation. J. Neurosurg. 111, 238-246. doi: 10.3171/2008.8.JNS08644

Zon, L. I., and Peterson, R. T. (2005). In vivo drug discovery in the zebrafish. Nat. Rev. Drug Discov. 4, 35-44. doi: 10.1038/nrd1606

Conflict of Interest: The authors declare that the research was conducted in the absence of any commercial or financial relationships that could be construed as a potential conflict of interest.

Copyright (c) 2021 Chen, Li, Yao and Jia. This is an open-access article distributed under the terms of the Creative Commons Attribution License (CC BY). The use, distribution or reproduction in other forums is permitted, provided the original author(s) and the copyright owner(s) are credited and that the original publication in this journal is cited, in accordance with accepted academic practice. No use, distribution or reproduction is permitted which does not comply with these terms. 